TITLE:

\title{
Blend miscibility of cellulose propionate with poly(N-vinyl pyrrolidone-co-methyl methacrylate).
}

\section{$\operatorname{AUTHOR}(\mathrm{S})$ :}

Sugimura, Kazuki; Teramoto, Yoshikuni; Nishio, Yoshiyuki

\section{CITATION:}

Sugimura, Kazuki ... [et al]. Blend miscibility of cellulose propionate with poly(N-vinyl pyrrolidone-co-methyl methacrylate).. Carbohydrate polymers 2013, 98(1): 532-541

\section{ISSUE DATE:}

2013-10-15

URL:

http://hdl.handle.net/2433/179398

\section{RIGHT:}

(C) 2013 Elsevier Ltd.; This is not the published version. Please cite only the published version.; この論文は出版社版でありません。引用の際に は出版社版をご確認ご利用ください。 
1 Blend miscibility of cellulose propionate with poly $(N$-vinyl pyrrolidone-co-methyl

2 methacrylate)

3

4

5 Kazuki Sugimura, Yoshikuni Teramoto, Yoshiyuki Nishio*

6

7 Division of Forest and Biomaterials Science, Graduate School of Agriculture, Kyoto

8 University, Sakyo-ku, Kyoto 606-8502, Japan

9

10 *Corresponding author. Tel.: +81 75753 6250; fax: +81 757536300 .

11 E-mail address: ynishio@kais.kyoto-u.ac.jp (Y. Nishio). 


\section{ABSTRACT}

The blend miscibility of cellulose propionate $(\mathrm{CP})$ with poly $(N$-vinyl pyrrolidone-co-methyl methacrylate) (P(VP-co-MMA)) was investigated. The degree of substitution (DS) of CP used ranged from 1.6 to $>2.9$, and samples for the vinyl polymer component were prepared in a full range of VP:MMA compositions. Through DSC analysis and solid-state ${ }^{13} \mathrm{C}$ NMR and FT-IR measurements, we revealed that CPs of DS $<2.7$ were miscible with $\mathrm{P}(\mathrm{VP}-$ co-MMA)s of $\mathrm{VP} \geq \sim 10 \mathrm{~mol} \%$ on a scale within a few nanometers, in virtue of hydrogen-bonding interactions between CP-hydroxyls and VP-carbonyls. When the DS of CP exceeded 2.7, the miscibility was restricted to the polymer pairs using $\mathrm{P}(\mathrm{VP}-\mathrm{co}-\mathrm{MMA}) \mathrm{s}$ of $\mathrm{VP}=\mathrm{ca} .10-40$ mol\%; the scale of mixing in the blends concerned was somewhat larger (ca. 5-20 nm), however. The appearance of such a "miscibility window" was interpretable as an effect of intramolecular repulsion in the copolymer component. Results of DMA and birefringence measurements indicated that the miscible blending of $\mathrm{CP}$ with the vinyl polymer invited synergistic improvements in thermomechanical and optical properties of the respective constituent polymers. Additionally, it was found that the VP:MMA composition range corresponding to the miscibility window was expanded by modification of the CP component into cellulose acetate propionate.

Keywords: Blend miscibility; Cellulose propionate; Poly $(N$-vinyl pyrrolidone-co-methyl methacrylate); Scale of homogeneity; Synergistic effect 


\section{Introduction}

Organic esters of cellulose (CEs) are industrially important materials utilized in various fields including molded plastics, fibers, optical films, membranes, coatings, and so forth (Edgar et al., 2001). For improvement in physical properties of CEs toward their further applications, the blending with other polymers can be a significant method, and a number of fundamental studies of CE blends have been carried out (Nishio, 2006). The authors' group has thus far investigated the blend miscibility of CEs with two different types of polymers, namely, biodegradable aliphatic polyesters such as poly( $\varepsilon$-caprolactone) (Higeshiro et al., 2009; Kusumi et al., 2008; Nishio et al., 1997) and synthetic vinyl polymers (Miyashita et al., 2002; Ohno et al., 2005; Ohno \& Nishio, 2006; Ohno \& Nishio, 2007a; Sugimura et al., 2013; Yoshitake et al., 2013).

With regard to the CE/vinyl polymer blends, three separate systems of cellulose acetate (CA), propionate $(\mathrm{CP})$, and butyrate $(\mathrm{CB})$, each blended with $\mathrm{P}(\mathrm{VP}-\mathrm{co}-\mathrm{VAc})$, were examined mainly by differential scanning calorimetry (DSC); the counterpart P(VP-co-VAc) here represents homo- and random co-polymers comprising $N$-vinyl pyrrolidone (VP) and/or vinyl acetate (VAc) units. Figs. 1a-c survey the estimation results for the three systems, by offering each miscibility map constructed as a function of the degree of ester substitution (DS) of CE and the VP:VAc composition of P(VP-co-VAc) (Miyashita et al., 2002; Ohno \& Nishio, 2006; Sugimura et al., 2013). As can readily be seen by comparison of the three maps, the region of miscible $\mathrm{CE} / \mathrm{P}(\mathrm{VP}-\mathrm{co}-\mathrm{VAc})$ pairings was drastically changeable depending on the carbon number of the acyl substituent of CE. Intriguingly, the CP system provided the largest miscible region (see Fig. 1b). Such a specific improvement in the miscibility with $\mathrm{P}(\mathrm{VP}-\mathrm{co}$-VAc) of the $\mathrm{CP}$ blends was attributed to the structural affinity favorable for a dipole-dipole antiparallel alignment between the propionyl side-group and the VAc unit, as well as to the moderate length of the acyl substituent which generally works as a 
steric hindrance to the hydrogen-bonding interactions associated with the residual hydroxyls (Sugimura et al., 2013).

Another system of CA/VP-containing vinyl copolymer blends was also reported on the miscibility and intermolecular interaction (Ohno \& Nishio, 2007a), wherein methyl methacrylate (MMA) was selected as the second constituent of the copolymer, because of the distinguished optical property, weather resistance, and safety to living bodies of poly(methyl methacrylate) (PMMA). Fig. 1d summarizes the result of miscibility estimation for the CA/P(VP-co-MMA) blends. Regarding this system, an additional interest was focused on the molecular orientation and optical anisotropy in uniaxially drawn films of the miscible blends (Ohno \& Nishio, 2007b); the birefringence development was widely controllable in both the degree and polarity, by altering the DS of CA, the VP:MMA ratio in P(VP-co-MMA), and the proportion of the mixing polymers. However, as mapped in Fig. 1d, the miscible pairing of this system was realized in a region of lower DS of CA and higher VP fraction in $\mathrm{P}(\mathrm{VP}-\mathrm{co}-\mathrm{MMA})$, and thus the blends were kind of a hydrophilic material.

As an extension of the blend studies stated above, our attention was then directed to the miscibility characterizations of $\mathrm{CP}$ and cellulose acetate propionate (CAP) with $\mathrm{P}(\mathrm{VP}-\mathrm{co}-\mathrm{MMA})$, in expectation of a positive effect of the propionyl substitution which would expand the DS and VP:MMA ranges for miscible pairing of CE and P(VP-co-MMA), as has been observed for the CE/P(VP-co-VAc) system. The miscibility attainment even for hydrophobic combinations of high-substituted CP or CAP and MMA-rich copolymer may be of great significance, in view of the practical application to optical films and/or membranes. In the present work, we inspected the main target system of $\mathrm{CP} / \mathrm{P}(\mathrm{VP}-\mathrm{co}-\mathrm{MMA})$ blends on the miscibility, inter-component interactions, and scale of homogeneity, by DSC and Fourier transform infrared (FT-IR) and solid-state ${ }^{13} \mathrm{C}$ NMR spectroscopy. In addition to the basic characterizations, some mechanical and optical properties in film form of the CP/P(VP-co-MMA) blends were also investigated by dynamic mechanical analysis (DMA) 
and birefringence measurements, respectively.

\section{Experimental}

\subsection{Materials}

CP samples were synthesized from cotton cellulose with a viscosity average molecular weight of 252,000 via a homogeneous reaction with acid chloride/base catalyst, in a procedure similar to that used in previous studies (Kusumi et al., 2008; Nishio et al., 1997). Two CAP samples were used; one was purchased from Eastman Chemical Co., and the other was obtained by acetylation of a commercial CP (Scientific Polymer Products, Inc.) in the same way as that adopted in a previous study (Aoki \& Nishio, 2010). Codes " $\mathrm{CP}_{x}$ " and "CA $\mathrm{CA}_{y}$ " denote $\mathrm{CP}$ of propionyl DS $=x$ and CAP of acetyl DS $=y$ and propionyl DS $=z$, respectively. Table 1 summarizes data of molecular weight and glass transition temperature $\left(T_{\mathrm{g}}\right)$ for all the CE samples used in this study. The vinyl polymers employed as a mixing partner for the CPs and CAPs were poly( $N$-vinyl pyrrolidone) (PVP), PMMA, and $\mathrm{P}(\mathrm{VP}-\mathrm{co}$-MMA) copolymers, basically the same as those in the preceding paper (Ohno \& Nishio, 2007a). Data of characterization for all the vinyl polymers are also listed in Table 1. As shown in the table, any of the $\mathrm{P}(\mathrm{VP}-\mathrm{co}-\mathrm{MMA})$ samples exhibited a single $T_{\mathrm{g}}$ and they were all regarded as essentially random copolymer. Hereafter, a P(VP-co-MMA) sample of VP:MMA $=m: n$ (in molar ratio) is encoded as $\mathrm{P}\left(\mathrm{VP}_{m}-c o-\mathrm{MMA}_{n}\right)$.

\subsection{Preparation of blend samples}


112 solution mixing and solvent evaporation in the same manner as that adopted in the preceding works (Ohno \& Nishio, 2007a; Sugimura et al., 2013). N,N-Dimethylformamide (DMF) was selected as a common solvent and the film casting was carried out at $50{ }^{\circ} \mathrm{C}$ under reduced pressure $(<10 \mathrm{mmHg})$. The as-cast samples were further dried at $50{ }^{\circ} \mathrm{C}$ in vacuo for 3 days.

2.3. Measurements

DSC was carried out with a Seiko DSC 6200/EXSTAR 6000 apparatus. The temperature readings were calibrated with an indium standard. The calorimetry measurements were conducted on ca. 5-mg samples packed in an aluminum pan under a nitrogen atmosphere. Each sample was first heated from ambient temperature $\left(\sim 25{ }^{\circ} \mathrm{C}\right)$ to $230{ }^{\circ} \mathrm{C}$ at a scanning rate of $20{ }^{\circ} \mathrm{C} \mathrm{min}^{-1}$, and then immediately quenched to $-50{ }^{\circ} \mathrm{C}$ at a rate of $80{ }^{\circ} \mathrm{C} \mathrm{min}{ }^{-1}$. Following this, the second heating scan was run from $-50{ }^{\circ} \mathrm{C}$ to $230{ }^{\circ} \mathrm{C}$ at a rate of $20{ }^{\circ} \mathrm{C} \min ^{-1}$ to record stable thermograms. For blend series of $\mathrm{CA}_{0.47} \mathrm{P}_{2.48}$, however, the upper limit of temperature in the heating scan was programmed to be $260{ }^{\circ} \mathrm{C}$, since a melting endotherm was predicted to appear above $230{ }^{\circ} \mathrm{C}$ due to some extent of crystallizability of the CAP. Thermograms presented in this paper were all obtained in the second heating scan, and the $T_{\mathrm{g}}$ was taken as a temperature at the midpoint of a baseline shift in heat flow characterizing the glass transition.

Shimazu IRPrestige-21 spectrometer. All the spectra were recorded at $20{ }^{\circ} \mathrm{C}$ in a transmission mode over a wavenumber range $400-4000 \mathrm{~cm}^{-1}$ with a resolution of $2 \mathrm{~cm}^{-1}$ via accumulation of 64 scans.

High-resolution solid-state NMR experiments were performed at $20{ }^{\circ} \mathrm{C}$ in a Varian NMR system $400 \mathrm{MHz}$ operated at a ${ }^{13} \mathrm{C}$ frequency of $100.6 \mathrm{MHz}$. The magic-angle spinning rate 
138 pulse width of $2.9 \mu \mathrm{s}$ was employed. In the measurements of $T_{1 \rho}{ }^{\mathrm{H}}$, a contact time of $0.2 \mathrm{~ms}$ was used, and a proton spin-locking time $\tau$ ranged from 0.5 to $30 \mathrm{~ms}$. 2048 scans were done to obtain the ${ }^{13} \mathrm{C} \mathrm{CP} / \mathrm{MAS}$ spectra, while 4096 scans were accumulated for the relaxation time measurements. Chemical shifts of ${ }^{13} \mathrm{C}$ spectra represented in ppm were referred to tetramethylsilane by using the methine carbon resonance $(29.47 \mathrm{ppm})$ of adamantane crystals as an external reference standard. In order to minimize any possible effect due to the thermal history and/or residual solvents, each sample was heat-treated at $250{ }^{\circ} \mathrm{C}$ in vacuo for 5 min just before the measurement.

DMA was conducted by using a Seiko DMS6100/EXSTAR6000 apparatus for film specimens prepared by hot-press molding $\left(230^{\circ} \mathrm{C}, 15 \mathrm{MPa}\right)$ of the solution-cast samples. Strips of rectangular shape $\left(20 \times 5 \mathrm{~mm}^{2}\right)$ cut from the molded films were used for measurements of the temperature dependence of the dynamic storage modulus $\left(E^{\prime}\right)$ and loss modulus $\left(E^{\prime \prime}\right)$. The measuring conditions were as follows: temperature range, $-150-300{ }^{\circ} \mathrm{C}$; scanning rate, $2{ }^{\circ} \mathrm{C} / \mathrm{min}$; oscillatory frequency, $10 \mathrm{~Hz}$. film.

\section{Results and discussion}




\subsection{Miscibility estimation by thermal analysis} 65

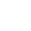

The miscibility state in the $\mathrm{CP}$ and CAP/vinyl polymer systems was estimated by $T_{\mathrm{g}}$ determination in DSC. In general, if any blend sample of a given polymer/polymer pair exhibits a single glass transition between the $T_{\mathrm{g}} \mathrm{S}$ of the two component polymers and a composition-dependent shift of the blend $T_{\mathrm{g}}$ is clearly observed, then the pair can be regarded as a miscible one on the $T_{\mathrm{g}}$-detection scale that is usually assumed to be less than a couple of tens of nanometers (Nishio, 1994; Ultracki, 1990).

\subsubsection{Overview}

Fig. 2a displays a miscibility map for the CP/P(VP-co-MMA) system, constructed as a function of DS of CP and VP fraction in P(VP-co-MMA). The data for a blend series of CP/PVP homopolymer was quoted from a previous paper (Sugimura et al., 2013). In perspective, polymer pairs composed of low-substituted CP and VP-rich P(VP-co-MMA) were judged to be miscible. This suggests the contribution of a hydrogen-bonding interaction between CP-hydroxyl and VP-carbonyl groups to the miscibility attainment. A definite "miscibility window" emerged in a hydrophobic region satisfying propionyl DS > 2.7 and VP fraction $=9-40$ mol\%. As mapped in Fig. 2b, CAP/P(VP-co-MMA) blends using partially acetylated $\mathrm{CA}_{0.16} \mathrm{P}_{2.52}$ and $\mathrm{CA}_{0.47} \mathrm{P}_{2.48}$ also imparted a miscibility window; interestingly, the VP:MMA range forming the window became expanded, compared with that for the corresponding $\mathrm{CP} / \mathrm{P}\left(\mathrm{VP}-\right.$ co-MMA) blends using $\mathrm{CP}_{2.72}$ or $\mathrm{CP}_{2.93}$. Actual observations in the thermal analysis for the present CE blends are described below in detail.

\subsubsection{CP/PMMA blends}

Fig. 3a illustrates DSC thermograms measured for a blend series of $\mathrm{CP}_{1.59} / \mathrm{PMMA}$ homopolymer. As can be seen from the data, two independent glass transitions originating 
190 from the two components were clearly detected for the blend samples of 20/80-80/20 compositions (in wt\% ratio). Therefore, we can judge the $\mathrm{CP}_{1.59} / \mathrm{PMMA}$ pair to be immiscible. However, the $T_{\mathrm{g}}$ of the PMMA component was prone to slightly shift to higher temperatures with an increase in the $\mathrm{CP}$ content, while the $T_{\mathrm{g}}$ of the $\mathrm{CP}$ component hardly shifted from the original position.

DSC measurements were also performed on the other eight series of CP/PMMA blends prepared by using CPs with different DS values ranging from 1.71 to 2.93. The data were all similar to that given in Fig. 3a; the thermograms indicated the presence of double $T_{\mathrm{g}} \mathrm{S}$ corresponding to those of the two constituent polymers, but habitually with some extent of elevation in the PMMA $T_{\mathrm{g}}$. It is thus reasonably concluded that all the CP/PMMA blends are substantially immiscible irrespective of the DS of the CP used, even though a certain level of compatibility of PMMA with CP may be admitted.

\subsection{3. $C P / P(V P-$ co-MMA) blends}

In visual appearance, as-cast films of CP blends with VP-MMA copolymers were homogeneous and highly transparent, except for cloudy films of several polymer pairs composed of CP of DS > 2.7 and $\mathrm{P}(\mathrm{VP}-$ co-MMA) having more than $50 \mathrm{~mol} \% \mathrm{VP}$ residues.

Any series of $\mathrm{CP}_{1.59} / \mathrm{P}(\mathrm{VP}-\mathrm{co}-\mathrm{MMA})$ blends, prepared by using the copolymers of VP:MMA $=9: 91-76: 24$, provided a smooth variation of a single $T_{\mathrm{g}}$ which was situated between the $T_{\mathrm{g}}$ values of the two unblended components (data not shown). Thus, it turned out that $\mathrm{CP}_{1.59}$ formed a miscible monophase with $\mathrm{P}(\mathrm{VP}-c o-\mathrm{MMA}) \mathrm{s}$ of $\mathrm{VP} \geq 9 \mathrm{~mol} \%$. Similar miscible behavior was confirmed in the use of CPs of DS $=1.71-2.62$, as the thermal data is exemplified for $\mathrm{CP}_{1.71} / \mathrm{P}\left(\mathrm{VP}_{0.22}-\right.$ co- $\left.\mathrm{MMA}_{0.78}\right)$ blends in Fig. 3b. We should note here that the CPs of DS $<2.7$ were miscible with $\mathrm{P}(\mathrm{VP}-c o-\mathrm{MMA})$ s of extremely low VP fractions such as $10-30 \mathrm{~mol} \%$, because the same situation was never realized for the previous system employing CA (see Fig. 1d). 
Another noteworthy finding was that even high-substituted CPs of DS > 2.7 made a miscible combination with MMA-rich P(VP-co-MMA)s having ca. 10-40 mol\% VP residues, despite the immiscibility of the CPs with PVP and PMMA homopolymers. Fig. 3c exemplifies several DSC thermograms obtained for a polymer combination of $\mathrm{CP}_{2.72} / \mathrm{P}\left(\mathrm{VP}_{0.32}-\right.$ co- $\left.\mathrm{MMA}_{0.68}\right)$; all the samples of $10 / 90-90 / 10$ compositions gave a single $T_{\mathrm{g}}$. Thus, decidedly, the CP/P(VP-co-MMA) system exhibited a miscibility window. The advent of such a window was unacceptable as to the CA/P(VP-co-MMA) system, but observed previously for the $\mathrm{CP} / \mathrm{P}(\mathrm{VP}-\mathrm{co}-\mathrm{VAc})$ and $\mathrm{CB} / \mathrm{P}(\mathrm{VP}-\mathrm{co}-\mathrm{VAc})$ systems (see Figs. $1 \mathrm{~b}$ and 1c) (Sugimura et al, 2013; Ohno \& Nishio, 2006). In these earlier studies, it was concluded that a greater repulsion between the VP and VAc units in the random copolymer was mainly contributory to the miscibility attainment; this was rationalized by assessment of Krigbaum-Wall interaction parameters $(\mu)$ for the ingredient polymer pairs involving in the CB/P(VP-co-VAc) system (Ohno \& Nishio, 2007a). The intramolecular copolymer effect may also be applicable to the present $\mathrm{CP}(\mathrm{DS}>2.7) / \mathrm{P}(\mathrm{VP}-$ co-MMA $)$ blends. The absence of such a clear miscibility window in the map of the CA/P(VP-co-MMA) system (Fig. 1d) is due to an inhibiting factor, i.e., the strong self-association ability of highly substituted CAs of DS $>2.7$; the CAs are rather easily crystallizable as cellulose triacetate II.

In comparison between the two maps (Figs. 1b and 2a) for the $\mathrm{CP}$ blends combined with different copolymers, $\mathrm{P}(\mathrm{VP}-\mathrm{co}-\mathrm{VAc})$ and $\mathrm{P}(\mathrm{VP}-\mathrm{co}-\mathrm{MMA})$, obviously, the window region for the $\mathrm{CP} / \mathrm{P}(\mathrm{VP}-$ co-MMA) system is narrower than that for the $\mathrm{CP} / \mathrm{P}(\mathrm{VP}-$ co-VAc) system. Again, from estimation of the interaction parameters for the two units constituting the respective copolymers concerned (Ohno \& Nishio, 2007a), it has been derived that the constituents VP and VAc in $\mathrm{P}(\mathrm{VP}-\mathrm{co}-\mathrm{VAc})$ strike an intense repellent character to each other, while the VP and MMA units in $\mathrm{P}(\mathrm{VP}-$-co-MMA) show a relatively weaker repulsive interaction. Presumably, this deterioration of the intramolecular repulsive action in the $\mathrm{P}(\mathrm{VP}-\mathrm{co}-\mathrm{MMA})$ copolymer is responsible for the appearance of the narrower window in the 
CP/P(VP-co-MMA) map (Fig. 2a).

\subsection{4. $C A P / P(V P-c o-M M A)$ blends}

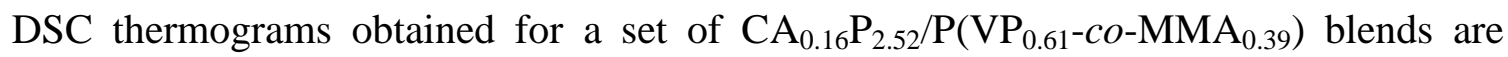
displayed in Fig. 3d; we can see a single $T_{\mathrm{g}}$ shifting to lower temperatures along with an increase in the $\mathrm{P}\left(\mathrm{VP}_{0.61}-\right.$ co- $\left.\mathrm{MMA}_{0.39}\right)$ content. Such a miscible sign was observed for blend series of this CAP with $\mathrm{P}(\mathrm{VP}-\mathrm{co}-\mathrm{MMA}) \mathrm{s}$ of $\mathrm{VP}=13-76 \mathrm{~mol} \%$, but never done for the CAP blends with PVP and PMMA homopolymers.

Fig. 3e shows a miscible evidence by $\mathrm{DSC}$ for a $\mathrm{CA}_{0.47} \mathrm{P}_{2.48} / \mathrm{P}\left(\mathrm{VP}_{0.09}-\right.$ co- $\left.-\mathrm{MMA}_{0.91}\right)$ combination using another CAP sample. Differing from the overall amorphous behavior of $\mathrm{CA}_{0.16} \mathrm{P}_{2.52}$, the $\mathrm{CA}_{0.47} \mathrm{P}_{2.48}$ sample exhibited an exothermic peak $\left(180{ }^{\circ} \mathrm{C}\right)$ and an endothermic peak $\left(240{ }^{\circ} \mathrm{C}\right)$ after onset of the glass transition $\left(T_{\mathrm{g}}=132{ }^{\circ} \mathrm{C}\right)$; the two peaks are ascribable to a so-called cold-crystallization and subsequent melting of the formed crystal, respectively. Such crystallizability was also noticed for $\mathrm{CP}_{2.93}$ of DS $>2.9$, but the crystalline phase was formed in somewhat slower crystallization kinetics. Despite of the crystalline habit common to tri-esterified celluloses, as exemplified in Fig. $3 \mathrm{e}$, the $\mathrm{CA}_{0.47} \mathrm{P}_{2.48}$ blends with $\mathrm{P}\left(\mathrm{VP}_{0.09}\right.$-co-MMA $\left.\mathrm{M}_{0.91}\right)$ exhibited a definitely single composition-dependent $T_{\mathrm{g}}$ and then produced a systematic depression in the melting point of the induced CAP crystal. This coupled thermal behavior is typical of that of miscible blends composed of a pair of crystallizable polymer/amorphous polymer (MacKnight et al., 1978). Similar DSC data were obtained for additional six combinations of $\mathrm{CA}_{0.47} \mathrm{P}_{2.48}$ with $\mathrm{P}(\mathrm{VP}-c o-\mathrm{MMA}) \mathrm{s}$ of $\mathrm{VP}=$ $13-50 \mathrm{~mol} \%$.

Fig. 2b summarizes the miscibility estimation for the CAP/P(VP-co-MMA) series using $\mathrm{CA}_{0.16} \mathrm{P}_{2.52}$ and $\mathrm{CA}_{0.47} \mathrm{P}_{2.48}$, as a function of $\mathrm{VP}$ fraction in $\mathrm{P}(\mathrm{VP}-$ co-MMA); the corresponding data for comparable $\mathrm{CP} / \mathrm{P}\left(\mathrm{VP}-\right.$ co-MMA) blends using $\mathrm{CP}_{2.72}$ and $\mathrm{CP}_{2.93}$ are also shown there. The two CAPs may be regarded as derivatives obtained from CPs of DS $\approx 2.7$ and 2.95, 
respectively, by partial ester exchange for acetyl substitution. Plainly, both the CAP/P(VP-co-MMA) series offer the miscibility window, as did the blend series using CPs of DS $\geq \sim 2.7$; again, the intramolecular repulsion in the vinyl copolymer would be principally responsible for the observation. However, the range of copolymer composition forming the miscibility window is much wider in the CAP series, compared with that in the CP series of the corresponding DS in total. This expansion of the window might be ascribed to an additional repulsion effect originating in the CAP side. That is, the cellulose mixed ester would also behave as a kind of copolymer dangling two different acyl side-groups along the carbohydrate backbone. A similar deal of cellulose alkyl esters as copolymer has been made in a few reports on their structural characteristics (Buchanan et al., 1996; Frazier \& Glasser, 1995; Ohno \& Nishio, 2006). Therefore, the CAP/P(VP-co-MMA) blends are actually taken as a copolymer/copolymer system, where the miscibility should be affected by the duplicate, intramolecular copolymer effect.

\subsection{Spectroscopic analysis of intermolecular interaction and mixing scale}

\subsubsection{FT-IR spectra}

Fig. 4 compiles FT-IR spectra obtained for blends of the miscible $\mathrm{CP}_{1.71} / \mathrm{P}\left(\mathrm{VP}_{0.22}\right.$-co-MMA $\left.\mathrm{MM}_{0.78}\right)$ pair, particularly focusing on two regions of (a) $\mathrm{O}-\mathrm{H}$ and (b) $\mathrm{C}=\mathrm{O}$ stretching vibrations. Frequency shift and/or shape variation are clearly observed for the specific IR bands as a result of the hydrogen-bonding formation between the residual hydroxyls of the CP component and the VP-carbonyls of the copolymer. As shown in Fig. 4a, a band centering at $3482 \mathrm{~cm}^{-1}$ (top data), which can be associated with a mixture of free hydroxyls and intramolecularly hydrogen-bonded $\mathrm{OH}$ groups in the unblended $\mathrm{CP}$, shifted to lower wavenumber positions with increasing $\mathrm{P}(\mathrm{VP}-$ co-MMA) content. Concomitantly, another shoulder band became discernible on the side of further lower wavenumbers, as 
294 indicated by a white arrow at $\sim 3300 \mathrm{~cm}^{-1}$ in Fig. 4a. This new band can be ascribed to the stretching of intermolecularly hydrogen-bonded OH groups (Marchessault \& Liang, 1960). VP-carbonyl stretching vibration in the copolymer became asymmetric progressively as the $\mathrm{CP}$ content increased in the binary blend system. Consequently, the absorption band was dividable into two peaks, larger and smaller ones at $\sim 1685 \mathrm{~cm}^{-1}$ and $\sim 1660 \mathrm{~cm}^{-1}$, respectively (see enlarged data in the range of $1650-1700 \mathrm{~cm}^{-1}$ ). These two IR signals for the VP unit of the copolymer may be associated with the free carbonyl and hydrogen-bonded carbonyl

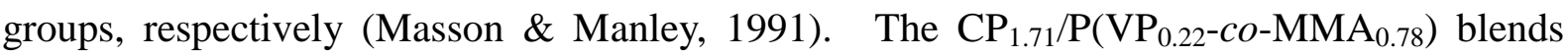
provided an additional single band centering at $1730-1740 \mathrm{~cm}^{-1}$, but this band was virtually made up of a prorated mixture of two carbonyl signals: a propionate $\mathrm{C}=\mathrm{O}$ peak $\left(1744 \mathrm{~cm}^{-1}\right)$ of the $\mathrm{CP}$ component and an MMA $\mathrm{C}=\mathrm{O}$ peak $\left(1727 \mathrm{~cm}^{-1}\right)$ of the copolymer component.

The inter-component interaction based on the hydrogen bonding of $\mathrm{OH}---\mathrm{O}=\mathrm{C}$, just as described above, was also ascertained not only for the blend series of $\mathrm{CP}_{1.71}$ with VP-rich $\mathrm{P}(\mathrm{VP}-\mathrm{co}-\mathrm{MMA}) \mathrm{s}$ including PVP, but also for other selected miscible pairs using CPs of DS < 2.7. For contradistinction, it should be recalled that CA of DS $=1.80$ never formed the same and the polymer pair was immiscible (see Fig. 1d). This contrast to the observation for the $\mathrm{CP}_{1.71} / \mathrm{P}\left(\mathrm{VP}_{0.22}-c o-\mathrm{MMA}_{0.78}\right)$ pair reflects the difference in self-association nature between $\mathrm{CA}$ and $\mathrm{CP}$, the former having the stronger ability.

When the copolymer $\mathrm{P}\left(\mathrm{VP}_{0.22}\right.$-co-MMA $\left.\mathrm{M}_{0.78}\right)$ was blended with $\mathrm{CP}_{2.89}$, however, there was no indication of such an intermolecular hydrogen-bonding interaction in IR examinations (data not shown). This result may be reasonable. With regard to the $\mathrm{CP}(\mathrm{DS}$ > 2.7)/P(VP-co-MMA) pairs constituting the miscibility window in Fig. 2a, the blend miscibility would be attained through the repulsion effect in the P(VP-co-MMA) side, not driven by direct attraction based on that hydrogen bonding. 
As a useful relaxation technique in solid-sate ${ }^{13} \mathrm{C}$ NMR, $T_{1 \rho}{ }^{\mathrm{H}}$ measurements for specific carbons in a multicomponent polymer system make it possible to estimate the mixing homogeneity in a scale of ${ }^{1} \mathrm{H}$ spin-diffusion length that is usually within several nanometers (Masson \& Manley, 1991; Ohno et al., 2005; Zhang et al., 1992); the dimensional limit is smaller than that $(\sim 20 \mathrm{~nm})$ detectable by DSC thermal analysis. $T_{1 \rho}{ }^{\mathrm{H}}$ values can be obtained by fitting the decaying carbon resonance intensity to the following exponential equation:

$$
M(\tau)=M(0) \exp \left(-\tau / T_{1 \rho}{ }^{\mathrm{H}}\right)
$$

where $M(\tau)$ is the magnetization intensity observed as a function of the spin-locking time $\tau$.

If two constituent polymers are homogeneously mixed on the scale over which ${ }^{1} \mathrm{H}$ spin-diffusion can take place in a time $T_{1 \rho}{ }^{\mathrm{H}}$, the $T_{1 \rho}{ }^{\mathrm{H}}$ values for different protons belonging to the respective components may be equalized to each other by the spin diffusion.

Using the above technique, we made a comparative assessment of the mixing scale for the two miscible series of blends: $\mathrm{CP}_{1.71} / \mathrm{P}\left(\mathrm{VP}_{0.22}-\right.$ co- $\left.-\mathrm{MMA}_{0.78}\right)$ and $\mathrm{CP}_{2.89} / \mathrm{P}\left(\mathrm{VP}_{0.22}\right.$-co- $\left.\mathrm{MMA}_{0.78}\right)$, the driving factor contributory to the respective miscibility attainments being the intermolecular hydrogen-bonding interaction (for the former) or the intramolecular repulsion effect in the copolymer (for the latter). Fig. 5 exemplifies ${ }^{13} \mathrm{C}$

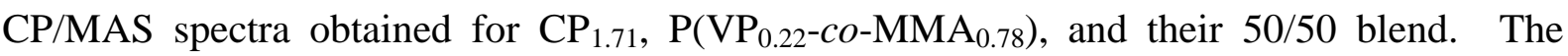
peak assignments of the spectra are based on literature data for CP (Tezuka \& Tsuchiya, 1995), PVP (Zhang et al., 1992), and PMMA (Liu et al., 1994). The experiment of $T_{1 \rho}{ }^{\mathrm{H}}$ quantifications was conducted through monitoring the following ${ }^{13} \mathrm{C}$ resonance signals with better resolutions: C2/C3/C5 pyranose carbons (74 ppm) and propionyl carbons C8 (28 ppm) and C9 (9.3 ppm) for the CP component, and $\mathrm{C}_{\alpha} / \mathrm{C}_{\varepsilon}(52 \mathrm{ppm}), \mathrm{C}_{\mathrm{b}} / \mathrm{C}_{\mathrm{c}} / \mathrm{C}_{\beta}(45 \mathrm{ppm})$, and $\mathrm{C}_{\mathrm{d}} / \mathrm{C}_{\gamma}$ carbons (18 ppm) for the P(VP-co-MMA) component. Carbonyl carbons were not adoptable 
merged into the other split signal of VP/MMA carbonyls ( 174/177 ppm) of the copolymer.

Fig. 6 illustrate the decay behavior in intensity of the $C 2 / C 3 / C 5$ and $C_{b} / C_{c} / C_{\beta}$ peaks for unblended $\mathrm{CP}\left(\mathrm{CP}_{1.71}\right.$ or $\left.\mathrm{CP}_{2.89}\right)$ and $\mathrm{P}\left(\mathrm{VP}_{0.22}-\right.$ co- $\left.\mathrm{MMA}_{0.78}\right)$, respectively, and also for their 50/50 blend imparting both resonance signals. The slope of each semi-logarithmic plot corresponds to an inverse of $-T_{1 \rho}{ }^{\mathrm{H}}$. The $T_{1 \rho}{ }^{\mathrm{H}}$ data thus estimated for $\mathrm{CP}_{1.71}, \mathrm{CP}_{2.89}$, $\mathrm{P}\left(\mathrm{VP}_{0.22}-\right.$ co- $\left.\mathrm{MMA}_{0.78}\right)$, and their miscible blends of $\mathrm{CP} / \mathrm{P}(\mathrm{VP}-$ co-MMA $)=75 / 25-25 / 75$ are all listed in Table 2.

As can be seen from Table 2 (upper part), $T_{1 \rho}{ }^{\mathrm{H}}$ of the $\mathrm{CP}_{1.71}$ component, originally 20.0 ms as an average, rises systematically with an increase in the copolymer component, while that of the $\mathrm{P}\left(\mathrm{VP}_{0.22}-c o-\mathrm{MMA}_{0.78}\right)$ component (average value of $23.6 \mathrm{~ms}$ ) diminishes correspondingly with increasing $\mathrm{CP}_{1.71}$ content. Consequently, the two $T_{1 \rho}{ }^{\mathrm{H}}$ values at every blend composition are in good agreement with each other. Thus, it is reasonably deduced that the two constituent polymers in the blends are intimately mixed within a range where the mutual ${ }^{1} \mathrm{H}$-spin diffusion is permitted over a period of the respective homogenized $T_{1 \rho}{ }^{\mathrm{H}}$, e.g., $\sim 22 \mathrm{~ms}$ for the 50/50 composition.

An effective path length $L$ of the spin diffusion in a time $T_{1 \rho}{ }^{\mathrm{H}}$ is given by the following equation (McBrierty \& Douglass, 1981):

$$
L \cong\left(6 D T_{1 \rho}{ }^{\mathrm{H}}\right)^{1 / 2}
$$

where $D$ is the spin-diffusion coefficient, usually taken to be $\sim 1.0 \times 10^{-12} \mathrm{~cm}^{2} \mathrm{~s}^{-1}$ in organic polymer materials (Assink, 1978; Masson \& Manley, 1991; Radloff et al., 1996). By

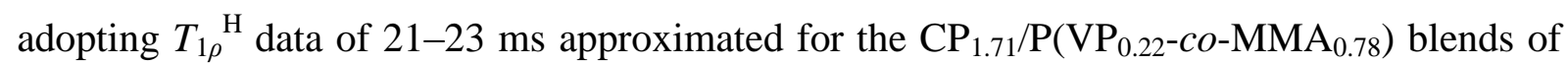
$75 / 25-25 / 75$ compositions, the diffusion path length is calculated as $L=3.5-3.7 \mathrm{~nm}$. Accordingly, it is confirmed that the relevant miscible series of hydrogen-bonding type is virtually homogeneous in a scale of ca. $4 \mathrm{~nm}$.

With regard to the $\left.\mathrm{CP}_{2.89} / \mathrm{P}_{\left(\mathrm{VP}_{0.22}-\text { co- }\right.} \mathrm{MMA}_{0.78}\right)$ series, on the contrary, $T_{1 \rho}{ }^{\mathrm{H}} \mathrm{s}$ of the two components at every blend composition never became so close to each other (see Fig. 6b and 
Table 2 (lower part)). This temporal disagreement implies that the relaxation processes of the two polymers in the blends progressed independently without their cooperative spin diffusion; thus the blends were found to be heterogeneous when viewed in a few nanometers scale by $T_{1 \rho}{ }^{\mathrm{H}}$ measurements. By the combined use of this result and the previous DSC data, it can be judged that the scale of homogeneity in the $\mathrm{CP}_{2.89} / \mathrm{P}\left(\mathrm{VP}_{0.22}-\right.$ co- $\left.-\mathrm{MMA}_{0.78}\right)$ blends situated in the window region lies between approximately 5 and $20 \mathrm{~nm}$.

\subsection{Synergistic effects on properties of $C P / P(V P-c o-M M A)$ films}

\subsubsection{Mechanical properties estimated by DMA}

Fig. 7a shows the temperature dependence of the dynamic storage modulus $E^{\prime}$ and loss

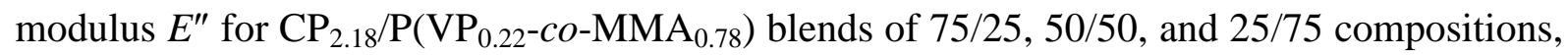
together with the corresponding data for plain $\mathrm{CP}_{2.18}$ and $\mathrm{P}\left(\mathrm{VP}_{0.22}-\right.$ co-MMA $\left.\mathrm{M}_{0.78}\right)$. As demonstrated clearly in the figure, the blend samples provided a single and sharp transition signal, both in the $E^{\prime}$ drop and in the $E^{\prime \prime}$ peak, which shifted systematically with the composition; this indicates a sign of good miscibility for the polymer pair. Similar behavior was observed for other test series including $\mathrm{CP}_{2.18} / \mathrm{PVP}$ and $\left.\mathrm{CP}_{2.89} / \mathrm{P}_{\left(\mathrm{VP}_{0.22}-\text { co- }\right.} \mathrm{MMA}_{0.78}\right)$ blends.

Fig. $7 \mathrm{~b}$ collects the glass-state modulus $E^{\prime}$ (at $20^{\circ} \mathrm{C}$ ) versus composition plots for the

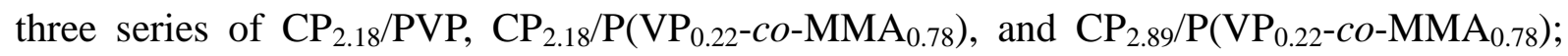
however, the modulus data for the PVP homopolymer per se was not obtained because of a brittle nature of the film. As can be seen from the plots in the figure, the modulus of any of the blend films was usually higher than those of the respective unblended $\mathrm{CP}$ and vinyl polymer samples. This result may be interpreted as a synergistic improvement in thermomechanical property of the cellulosic and vinyl polymer materials by miscible blending. Furthermore, we find by careful inspection that the rising level in the glassy 
modulus of the $\mathrm{CP}$ blends varied with difference in the driving force for the miscibility attainment; viz., the miscible blends of hydrogen-bonding type, referring to the $\mathrm{CP}_{2.18} / \mathrm{PVP}$ and $\mathrm{CP}_{2.18} / \mathrm{P}\left(\mathrm{VP}_{0.22}\right.$-co- $\left.\mathrm{MMA}_{0.78}\right)$ series, exhibited a noticeable elevation in the modulus $E^{\prime}$, whereas the $\left.\mathrm{CP}_{2.89} / \mathrm{P}_{\left(\mathrm{VP}_{0.22} \text {-co- }\right.} \mathrm{MMA}_{0.78}\right)$ series situated in the miscibility window showed a comparatively smaller increase in the $E^{\prime}$ value.

\subsubsection{Birefringence of $C P / P(V P-c o-M M A)$ films}

Optical birefringence derives from the orientation of polymer chains which have inherently the anisotropy of polarizability. In the simplest case of uniaxial stretching of amorphous homopolymers, the birefringence, defined as $\Delta n=n_{\|}-n_{\perp}$ with a refractive index $\left(n_{\|}\right)$parallel to the draw direction and that $\left(n_{\perp}\right)$ perpendicular to it, varies monotonically with the degree of orientation, according to the equation:

$$
\Delta n=\left\{\left(3<\cos ^{2} \omega>-1\right) \Delta n^{\circ}\right\} / 2
$$

where $\Delta n^{\circ}$ is an intrinsic birefringence for the perfect uniaxial orientation of polymer chains, and $\left\langle\cos ^{2} \omega\right\rangle$ is the second moment of orientation for an anisotropic segmental unit with a certain polarizability. In the case of the stretching of a blend composed of polymer 1 and polymer 2 , the birefringence $\Delta n$ of the deformed sample may be represented by

$$
\Delta n=v_{1} \Delta n_{1}+v_{2} \Delta n_{2}
$$

where $v_{i} \Delta n_{i}(i=1,2)$ indicates the contribution of an oriented polymer component $i$ to the total birefringence and $v_{i}$ denotes the volume fraction of that component.

Fig. 8 compiles results of the birefringence measurements conducted for drawn films of a

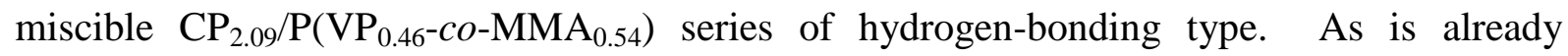
known (Ohno \& Nishio, 2007b), vinyl polymers comprising VP and/or MMA units, including the present $\mathrm{P}\left(\mathrm{VP}_{0.46}-c o-\mathrm{MMA}_{0.54}\right)$, exhibit negative optical anisotropy $\left(\Delta n_{\text {VP-MMA }}^{\mathrm{o}}<0\right)$ upon stretching of their films. On the other hand, as seen in the figure, the CP of DS $=2.09$ 
showed positive optical anisotropy $\left(\Delta n^{\mathrm{o}}{ }_{\mathrm{CP}}>0\right)$ on stretching of the film, and the birefringence increased sharply with the extent of elongation. The magnitude of $\Delta n$ evaluated for this CP was higher than that obtained previously for $\mathrm{CA}$ of $\mathrm{DS}=2.18$, when compared at a given stage of elongation; this suggests that a flexible methylene-methyl sequence in the propionyl side-group would be aligned parallel to the cellulose backbone, which contributes to the increase of the parallel component of refractive index $\left(n_{\|}\right)$.

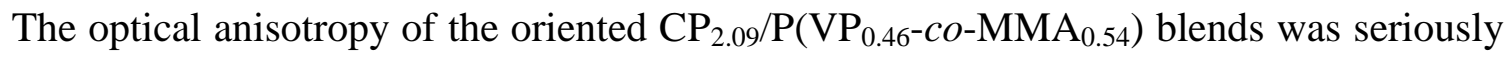
affected in both the polarity and degree, by the compensation effect due to the positive and negative contributions of the $\mathrm{CP}$ and copolymer components, respectively, to the overall birefringence. When the CP content reached $50 \mathrm{wt} \%$, the blend film assumed a character of birefringence-free material, as shown in Fig. 8. That is, the 50/50 blend can behave like an optically isotropic medium even though it should be mechanically anisotropic after deformation. A copolymer-rich sample of $\mathrm{CP}_{2.09} / \mathrm{P}\left(\mathrm{VP}_{0.46}-c o-\mathrm{MMA}_{0.54}\right)=30 / 70$ always provided negative birefringence, the absolute value of which was larger rather than that of the unblended copolymer. This result suggests that the orientation of the vinyl copolymer chains was enhanced in the presence of the CP component, possibly by virtue of the inter-component interaction that can occur through hydrogen bonding between the carbonyl and hydroxyl groups. The details of the actual molecular orientation behavior in these drawn blends will be investigated in a subsequent paper.

\section{Conclusions}

(Fig. 2a) was successfully constructed as a function of both the propionyl DS of CP and the VP:MMA composition of P(VP-co-MMA). Compared to the previous system using CA (Fig. 
1d), the miscible pairing region expanded to cover a considerably hydrophobic area of higher

DS and MMA-rich composition, with the advent of a miscibility window driven by repulsion between the comonomer units constituting $\mathrm{P}(\mathrm{VP}-$ co-MMA). However, the miscibility system (Fig. 1b), reflecting that the intramolecular repulsion in $\mathrm{P}(\mathrm{VP}-$ co-MMA) is weaker than that in $\mathrm{P}(\mathrm{VP}-\mathrm{co}-\mathrm{VAc})$.

From spectroscopic measurements by FT-IR and solid-state NMR, it was found that miscible blends composed of CP of DS $<2.7$ and $\mathrm{P}(\mathrm{VP}-\mathrm{co}-\mathrm{MMA})$ of $\mathrm{VP}>10 \mathrm{~mol} \%$ were substantially homogeneous on a scale within a few nanometers (e.g. $\sim 4 \mathrm{~nm}$ ), by virtue of the hydrogen-bonding formation between CP-hydroxyls and VP-carbonyls. On the other hand, miscible pairs using CPs of $\mathrm{DS} \geq 2.7$ and $\mathrm{P}(\mathrm{VP}-\mathrm{co}-\mathrm{MMA}) \mathrm{s}$ of $\mathrm{VP}=10-40 \mathrm{~mol} \%$, situated in the window region, produced blends having a somewhat larger size of homogeneity (ca. 5-20 $\mathrm{nm})$.

By DMA and birefringence measurements, we successfully demonstrated synergistic improvements in thermomechanical and optical properties of the miscible $\mathrm{CP} / \mathrm{P}(\mathrm{VP}-\mathrm{co}-\mathrm{MMA})$ blends. Particularly striking effects of the synergism were observed for the miscible blends of hydrogen-bonding type. With a certain specific polymer composition, the drawn blend can show a zero-birefringence character.

The miscibility characterization was also made for two CAP/P(VP-co-MMA) series using propionyl-rich CAPs; both the series also offered a miscibility window (Fig. 2b). It is astonishing that the range of copolymer composition forming the miscibility window was much wider in the CAP series, compared with that in the CP series of the corresponding DS in total. This expansion of the window would be ascribable to an additional repulsion effect originating in the CAP side; the blends concerned are therefore taken as a copolymer/copolymer system where the miscibility should be affected by the duplicated, 474 intramolecular copolymer effect. 
From a practical point of view, the present results will be of great significance for expanding the opportunities of material design based on the CE family. Further studies on the miscibility and interactions are now in progress for other combinations of CAPs of various acetyl/propionyl proportions with vinyl copolymers. Our insight will also be given into the molecular orientation behavior in drawn blends made up of a miscible pair of CP or CAP and $\mathrm{P}(\mathrm{VP}-\mathrm{co}-\mathrm{MMA})$, in relation to their birefringence characteristics as optical materials. These are topics to be reported in a subsequent paper.

\section{Acknowledgements}

This work was financed by a Grant-in-Aid for JSPS Fellows (No. 23-2809 to KS) as well as by a Grant-in-Aid for Scientific Research (A) (No. 23248026 to YN) from the Japan Society for the Promotion of Science.

\section{References}

Aoki, D., \& Nishio, Y. (2010). Phosphorylated cellulose propionate derivatives as thermoplastic flame resistant/retardant materials: influence of regioselective phosphorylation on their thermal degradation behaviour. Cellulose, 17, 963-976.

Assink, R. A. (1978). Nuclear spin diffusion between polyurethane microphases. Macromolecules, 11, 1233-1237.

Buchanan, C. M., Dorschel, D., Gardner, R. M., Komarek, R. J., Matosky, A. J., White, A. W., \& Wood, M. D. (1996). The influence of degree of substitution on blend miscibility and biodegradation of cellulose acetate blends. Journal of Environmental Polymer 
Degradation, 4, 179-195.

Edgar, K. J., Buchanan, C. M., Debenham, J. S., Rundquist, P. A., Seiler, B. D., Shelton, M. C., \& Tindall, D. (2001). Advances in cellulose ester performance and application. Progress in Polymer Science, 26, 1605-1688.

Frazier, C. E., \& Glasser, W. G. (1995). Intermolecular effects in cellulose mixed benzyl ethers blended with poly( $\varepsilon$-caprolactone). Journal of Applied Polymer Science, 58, $1063-1075$.

Higeshiro, T., Teramoto, Y., \& Nishio, Y. (2009). Poly(vinyl pyrrolidone-co-vinyl acetate)-graft-poly(e-caprolactone) as a compatibilizer for cellulose acetate/poly(E-caprolactone) blends. Journal of Applied Polymer Science, 113, 2945-2954.

Kusumi, R., Inoue, Y., Shirakawa, M., Miyashita, Y., \& Nishio, Y. (2008). Cellulose alkyl ester/poly( $\varepsilon$-caprolactone) blends: Characterization of miscibility and crystallization behaviour. Cellulose, 15, 1-16.

Liu, Y., Huglin, M. B., \& Davis, T. P. (1994). Preparation and characterization of some liner copolymers as precursors to thermoplastic hydrogels. European Polymer Journal, 30, $457-463$.

MacKnight, W. J., Karasz, F. E., \& Fried, J. R. (1978). Solid state transition behavior of blends. In D. R. Paul \& S. Newman (Eds.), Polymer blends, vol 1. (pp. 185-242). New York: Academic Press.

Marchessault, R. H., \& Liang, C. Y. (1960). Infrared spectra of crystalline polysaccharides. III. Marcerized cellulose. Journal of Polymer Science, 43, 71-84.

Masson, J. F., \& Manley, R. S. (1991). Miscible blends of cellulose and poly(vinylpyrrolidone). Macromolecules, 24, 6670-6679.

McBrierty, V. J., \& Douglass, D. C. (1981). Recent advances in the NMR of solid polymers. Journal of Polymer Science Macromolecular Reviews, 16, 295-366. 
Miyashita, Y., Suzuki, T., \& Nishio, Y. (2002). Miscibility of cellulose acetate with vinyl polymers. Cellulose, 9, 215-223.

Nishio, Y. (1994). Hyperfine composites of cellulose with synthetic polymers. In Gilbert R. D. (Ed.), Cellulosic polymers, blends and composites (pp. 95-113). Munich: Hanser.

Nishio, Y. (2006). Material functionalization of cellulose and related polysaccharides via diverse microcompositions. Advances in Polymer Science, 205, 97-151.

Nishio, Y., Matsuda, K., Miyashita, Y., Kimura, N., \& Suzuki, H. (1997). Blends of poly( $\varepsilon$-caprolactone) with cellulose alkyl esters: effect of the alkyl side-chain length and degree of substitution on miscibility. Cellulose, 4, 131-145.

Ohno, T., \& Nishio, Y. (2006). Cellulose alkyl ester/vinyl polymer blends: effects of butyryl substitution and intramolecular copolymer composition on the miscibility. Cellulose, 13, 245-259.

Ohno, T., \& Nishio, Y. (2007a). Estimation of miscibility and interaction for cellulose acetate and butyrate blends with $N$-vinylpyrrolidone copolymers. Macromolecular Chemistry and Physics, 208, 622-634.

Ohno, T., \& Nishio, Y. (2007b). Molecular orientation and optical anisotropy in drawn films of miscible blends composed of cellulose acetate and poly( $N$-vinylpyrrolidone-co-methyl methacrylate). Macromolecules, 40, 3468-3476.

Ohno, T., Yoshizawa, S., Miyashita, Y., \& Nishio, Y. (2005). Interaction and scale of mixing in cellulose acetate/poly( $N$-vinyl pyrrolidone-co-vinyl acetate) blends. Cellulose, 12, 281-291.

Radloff, D., Boeffel, C., \& Spiess, H. W. (1996). Cellulose and cellulose/poly(vinyl alcohol) blends. 2. Water organization revealed by solid-state NMR spectroscopy. Macromolecules, $29,1528-1534$.

Sugimura, K., Katano, S., Teramoto, Y., \& Nishio, Y. (2013). Cellulose propionate/poly( $N$-vinyl pyrrolidone-co-vinyl acetate) blends: dependence of the 
miscibility on propionyl DS and copolymer composition. Cellulose, 20, 239-252.

554

555

556

557

558

559

560

561

562

Tezuka, Y., \& Tsuchida, Y. (1995). Determination of substituent distribution in cellulose acetate by means of a ${ }^{13} \mathrm{C}$ NMR study on its propanoated derivative. Carbohydrate Research, 273, 83-91.

Utracki, L. A. (1990). Polymer alloys and blends: therymodynamics and rheology. Munich: Hanser.

Yoshitake, S., Suzuki, T., Miyashita, Y., Aoki, D., Teramoto, Y., \& Nishio, Y. (2013). Nanoincorporation of layered double hydroxides into a miscible blend system of cellulose acetate with poly(acryloyl morpholine). Carbohydrate Polymers, 93, 331-338.

Zhang, X. Q., Takegoshi, K., \& Hikichi, K. (1992). High-resolution solid-state C-13 nuclear magnetic resonance study on poly(vinyl alcohol)/poly(vinylpyrrolidone) blends. Polymer, $33,712-717$. 


\section{Figure Captions}

2

Fig. 1. Miscibility maps for four blend systems (a) CA/P(VP-co-VAc), (b) $\mathrm{CP} / \mathrm{P}(\mathrm{VP}-c o-\mathrm{VAc}),(\mathrm{c}) \mathrm{CB} / \mathrm{P}(\mathrm{VP}-\mathrm{co}-\mathrm{VAc})$, and (d) CA/P(VP-co-MMA), quoted from previous papers (Miyashita et al., 2002 for (a); Sugimura et al., 2013 for (b); Ohno \& Nishio, 2006 for (c); Ohno \& Nishio, 2007a for (d)) in a rearranged style retaining the essence.

Fig. 2. (a) Miscibility map for the blend system CP/P(VP-co-MMA), depicted as a function of DS of $\mathrm{CP}$ and VP fraction in $\mathrm{P}(\mathrm{VP}-\mathrm{co}-\mathrm{MMA})$, and (b) miscibility estimation for CAP/P(VP-co-MMA) blends using partially acetylated $\mathrm{CA}_{0.16} \mathrm{P}_{2.52}$ and $\mathrm{CA}_{0.47} \mathrm{P}_{2.48}$ as a function of $\mathrm{VP}$ fraction in $\mathrm{P}(\mathrm{VP}-\mathrm{co}-\mathrm{MMA})$, in comparison with the corresponding CP/P(VP-co-MMA) blends using $\mathrm{CP}_{2.72}$ and $\mathrm{CP}_{2.93}$, respectively. Symbols indicate that a given pair of $\mathrm{CP}$ or $\mathrm{CAP} / \mathrm{P}(\mathrm{VP}-$ co-MMA) is miscible $(\mathrm{O})$ or immiscible $(\mathrm{X})$.

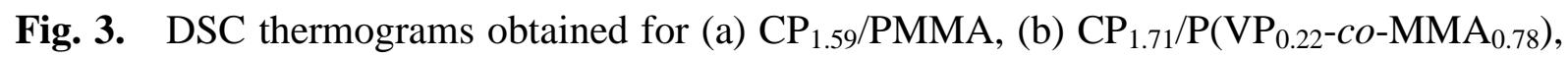
(c) $\quad \mathrm{CP}_{2.72} / \mathrm{P}\left(\mathrm{VP}_{0.32}-\right.$ co- $\left.\mathrm{MMA}_{0.68}\right)$,

(d) $\quad \mathrm{CA}_{0.16} \mathrm{P}_{2.52} / \mathrm{P}\left(\mathrm{VP}_{0.61}-c o-\mathrm{MMA}_{0.39}\right), \quad$ and

$\mathrm{CA}_{0.47} \mathrm{P}_{2.48} / \mathrm{P}\left(\mathrm{VP}_{0.09}-c o-\mathrm{MMA}_{0.91}\right)$ blends. Arrows indicate a $T_{\mathrm{g}}$ position taken as the midpoint of a baseline shift in heat flow.

Fig. 4. FT-IR spectra of $\mathrm{CP}_{1.71}, \mathrm{P}\left(\mathrm{VP}_{0.22}-c o-\mathrm{MMA}_{0.78}\right)$, and their blends in the frequency regions of (a) $\mathrm{O}-\mathrm{H}$ and (b) $\mathrm{C}=\mathrm{O}$ stretching vibrations. Data in the ranges of $3100-3500 \mathrm{~cm}^{-1}$ and $1650-1700 \mathrm{~cm}^{-1}$ are also shown on an enlarged scale. Solid arrows indicate a peak-top position in the respective specific absorption bands, and white arrows indicate a shoulder band associated with hydrogen bonding (see text for discussion).

Fig. 5. Solid-state ${ }^{13} \mathrm{C} C P / M A S ~ N M R$ spectra for $\mathrm{CP}_{1.71}, \mathrm{P}\left(\mathrm{VP}_{0.22}-c o-\mathrm{MMA}_{0.78}\right)$, and their 
50/50 blend.

Fig. 6. Semilogarithmic plots of the decay of ${ }^{13} \mathrm{C}$ resonance intensities as a function of

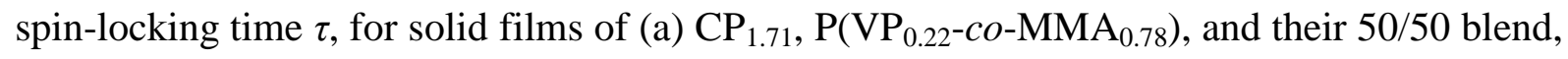
and (b) $\mathrm{CP}_{2.89}, \mathrm{P}\left(\mathrm{VP}_{0.22}-c o-\mathrm{MMA}_{0.78}\right)$, and their $50 / 50$ blend. The monitoring was conducted for the peak intensity of $\mathrm{C} 2 / \mathrm{C} 3 / \mathrm{C} 5$ pyranose carbons of $\mathrm{CP}$ and that of $\mathrm{C}_{\mathrm{b}} / \mathrm{C}_{\mathrm{c}} / \mathrm{C}_{\beta}$ carbons of the copolymer (see Fig. 5).

Fig. 7. (a) Temperature dependence of the dynamic storage modulus $E^{\prime}$ and loss modulus $E^{\prime \prime}$ for $\mathrm{CP}_{2.18} / \mathrm{P}\left(\mathrm{VP}_{0.22}\right.$-co-MMA $\left.\mathrm{M}_{0.78}\right)$ blends, and (b) the glassy state $E^{\prime}$ value (measured at $20{ }^{\circ} \mathrm{C}$ ) vs. composition plots for three series of blends, $\mathrm{CP}_{2.18} / \mathrm{PVP}, \mathrm{CP}_{2.18} / \mathrm{P}\left(\mathrm{VP}_{0.22}-\right.$ co- $\left.\mathrm{MMA}_{0.78}\right)$, and $\mathrm{CP}_{2.89} / \mathrm{P}\left(\mathrm{VP}_{0.22}-\right.$ co- $\left.\mathrm{MMA}_{0.78}\right)$

Fig. 8. Plots of birefringence $\Delta n \quad v s$. $\%$ elongation for drawn films of $\mathrm{CP}_{2.09} / \mathrm{P}\left(\mathrm{VP}_{0.46}\right.$-co-MMA $\left.\mathrm{MM}_{0.54}\right)$ blends. 
(a)

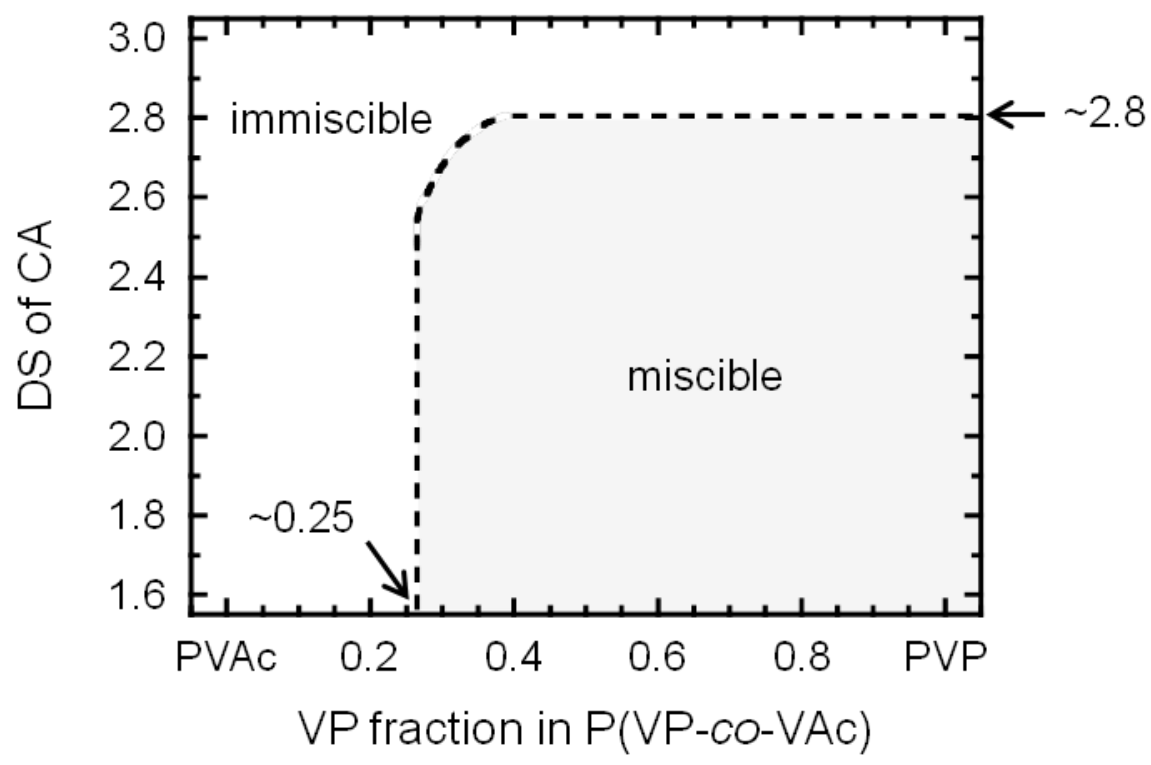

(b) $\quad \sim 0.10 \quad$ miscibility $\quad \sim 0.65$

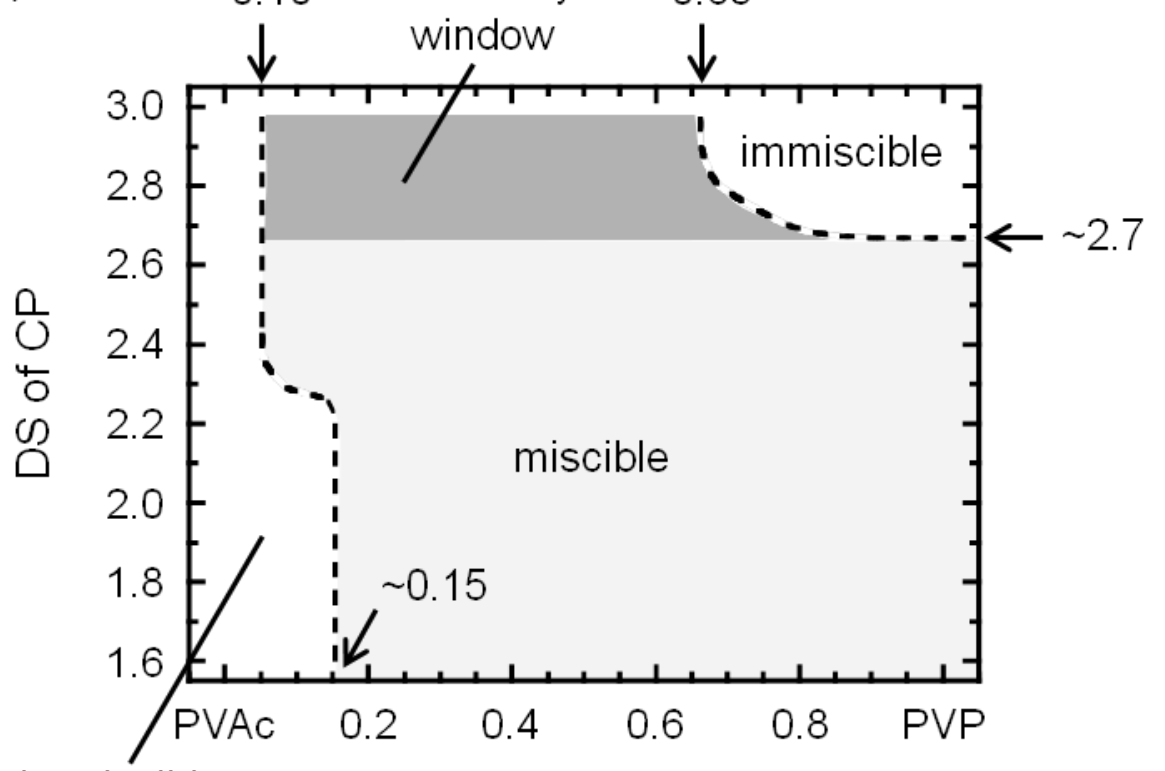

immiscible $V P$ fraction in $\mathrm{P}(\mathrm{VP}-\mathrm{co}-\mathrm{VAc})$ 
(c)

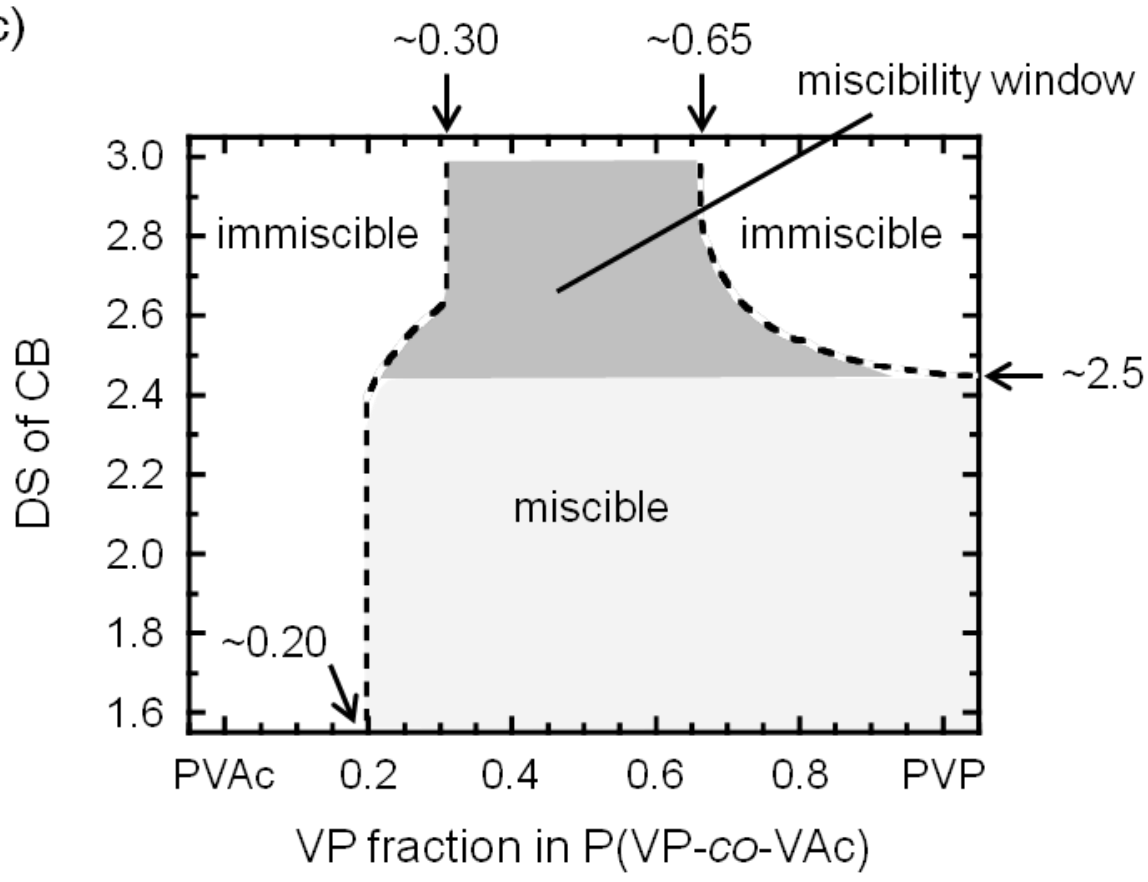

(d)

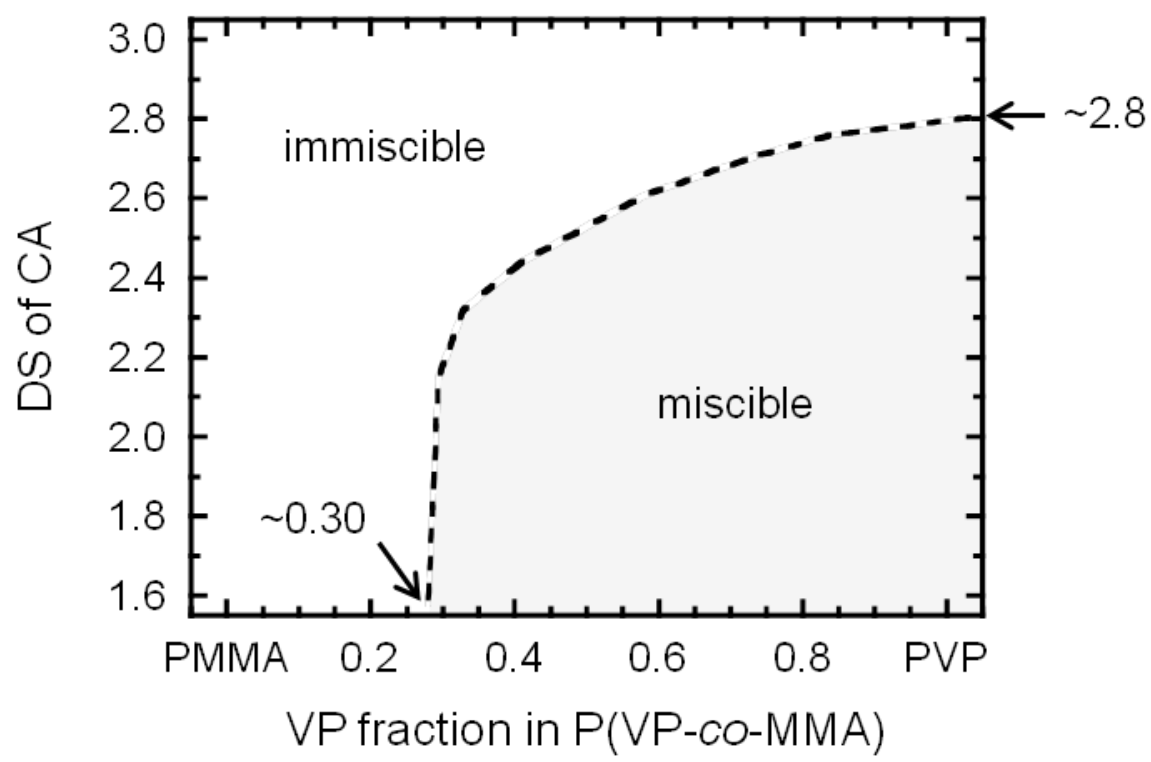


(a)

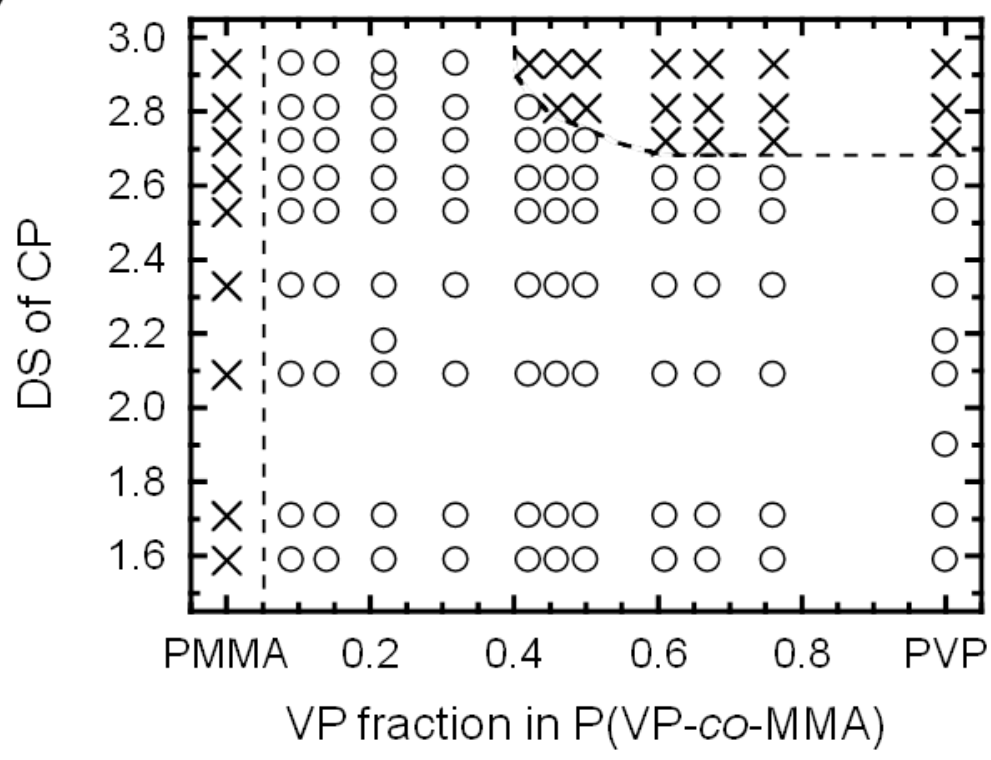

(b)

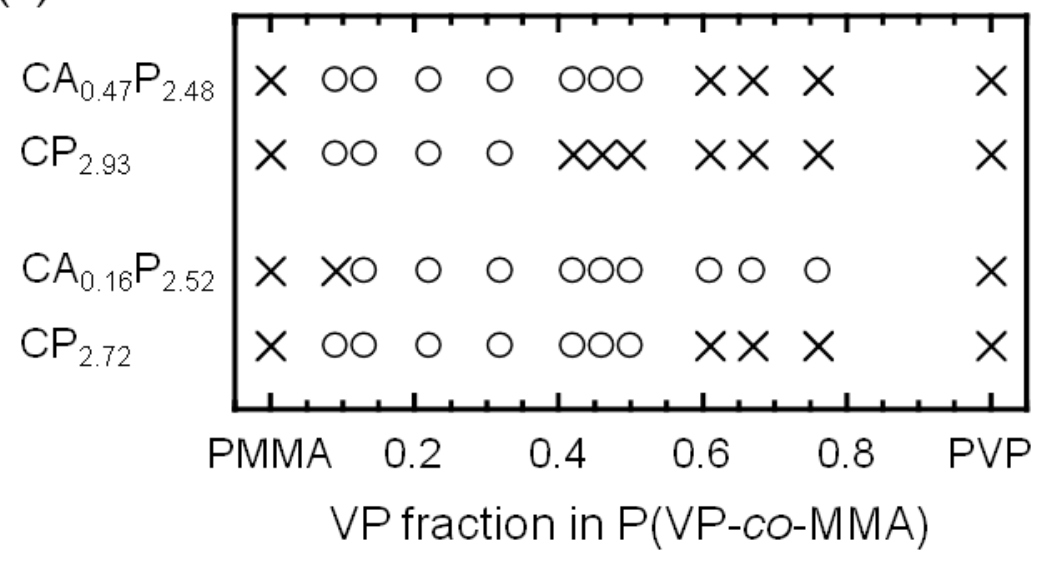

59 
(a)

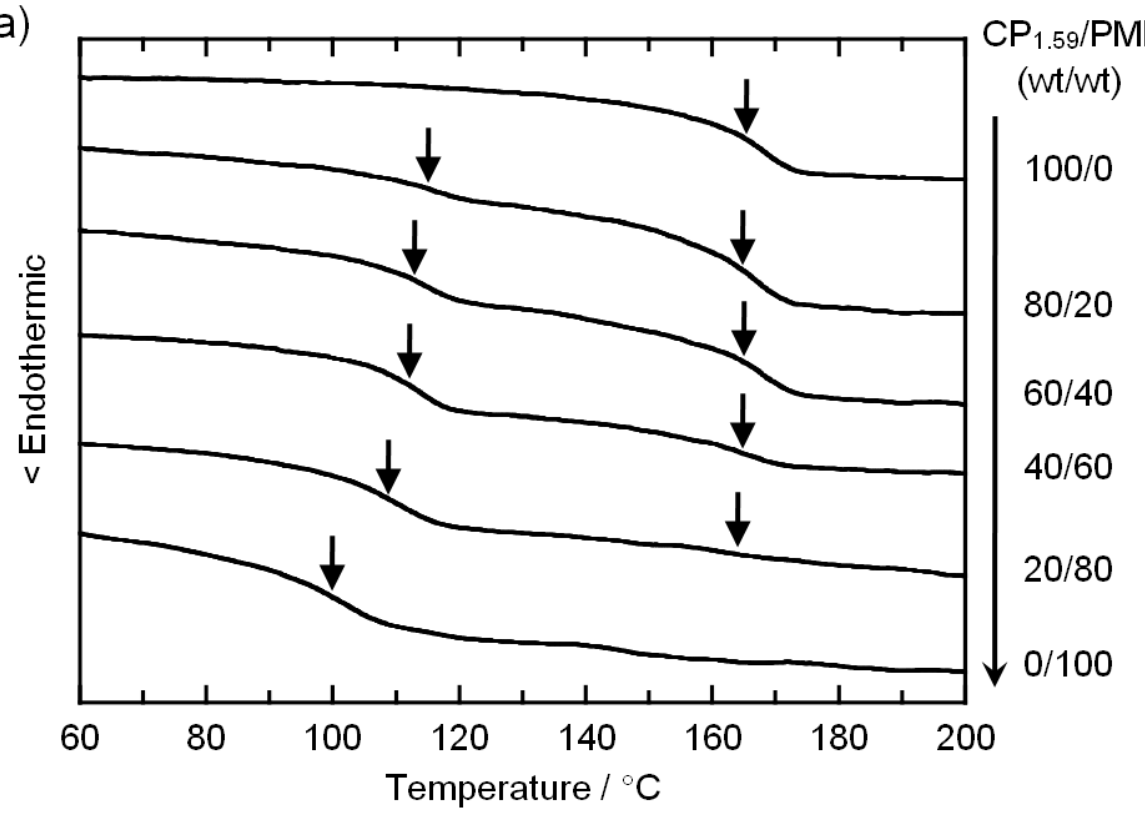

63

(b)

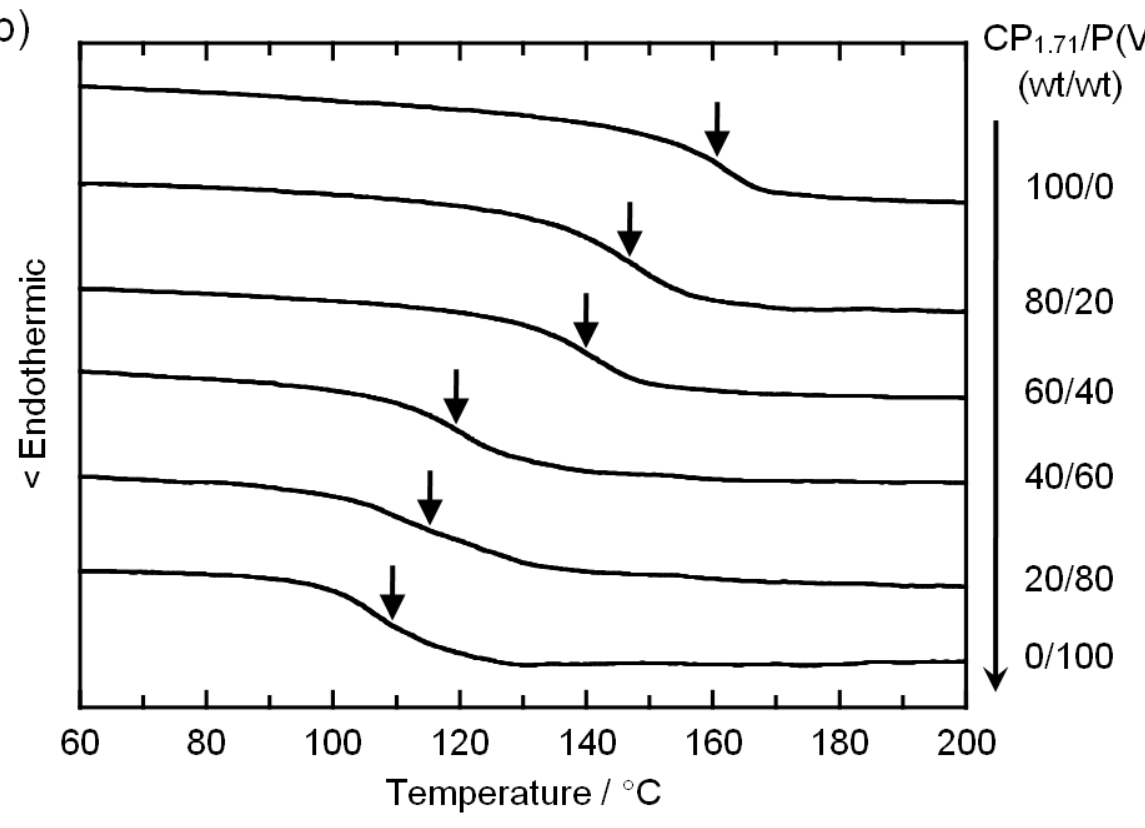

64

65

66

67

$<<$ Fig. 3. >> 
(c)

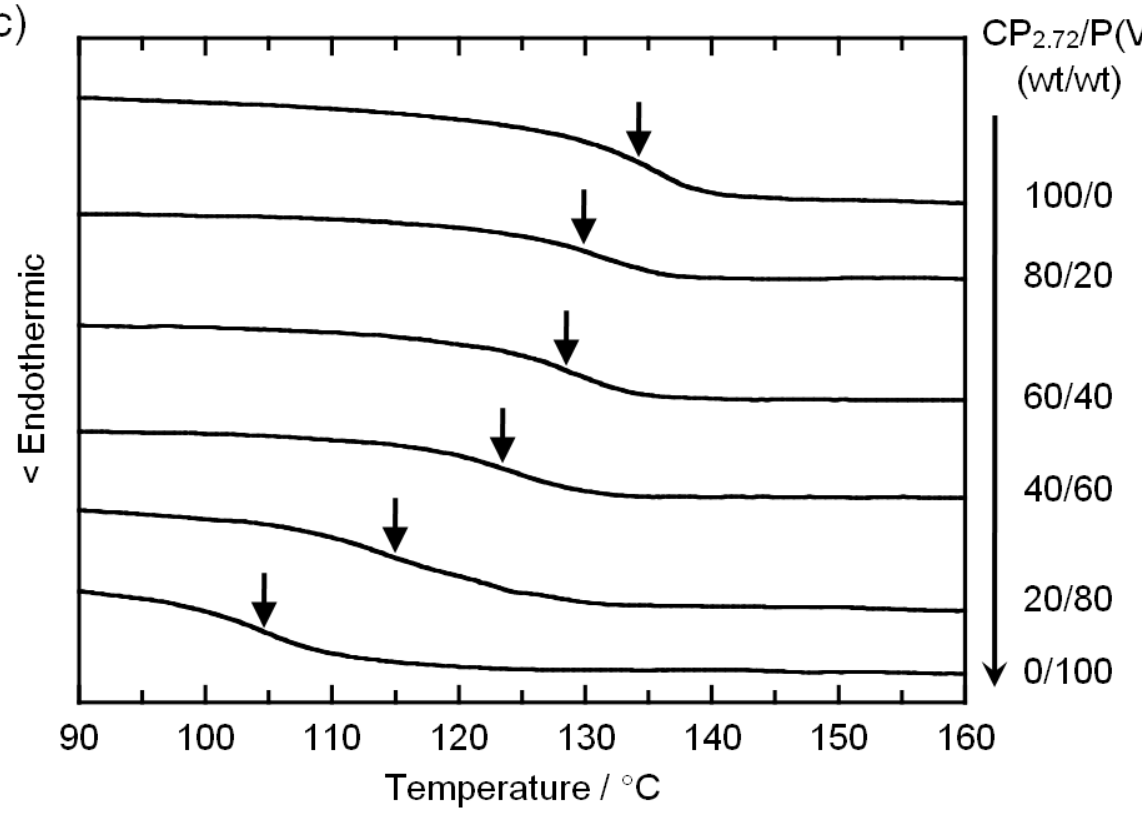

(d)

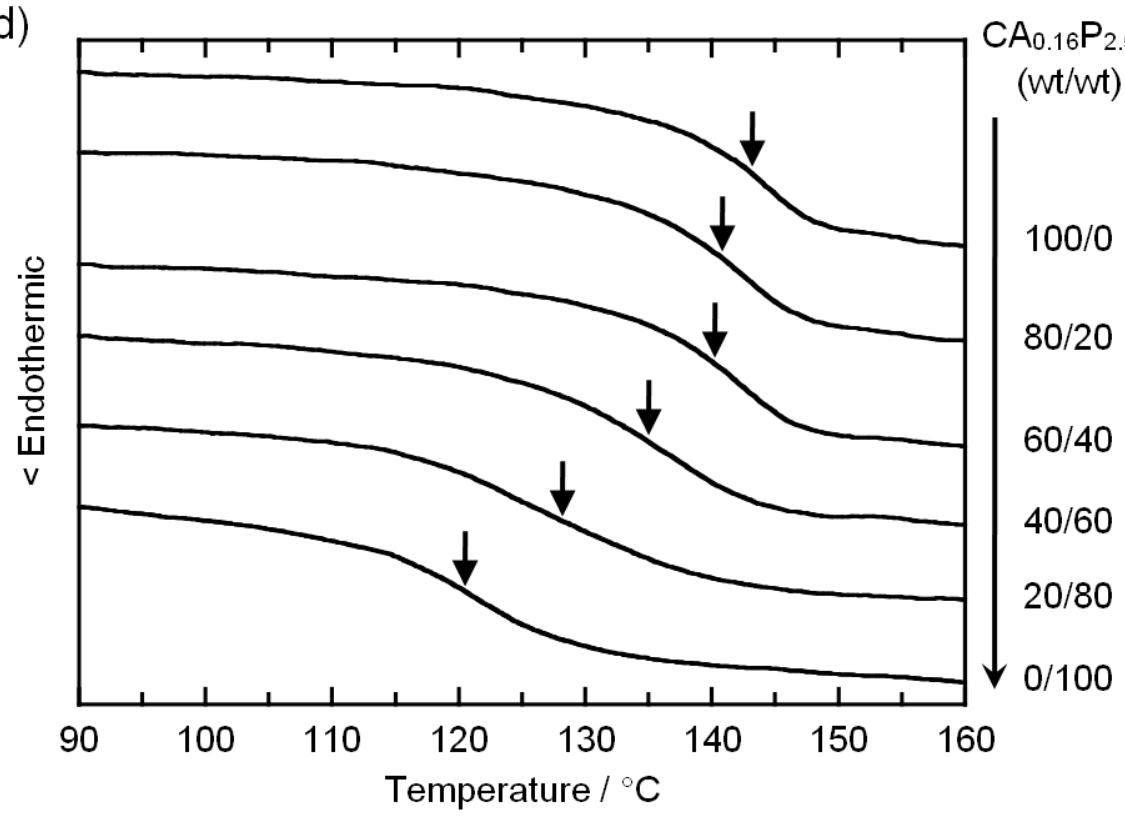


(e)

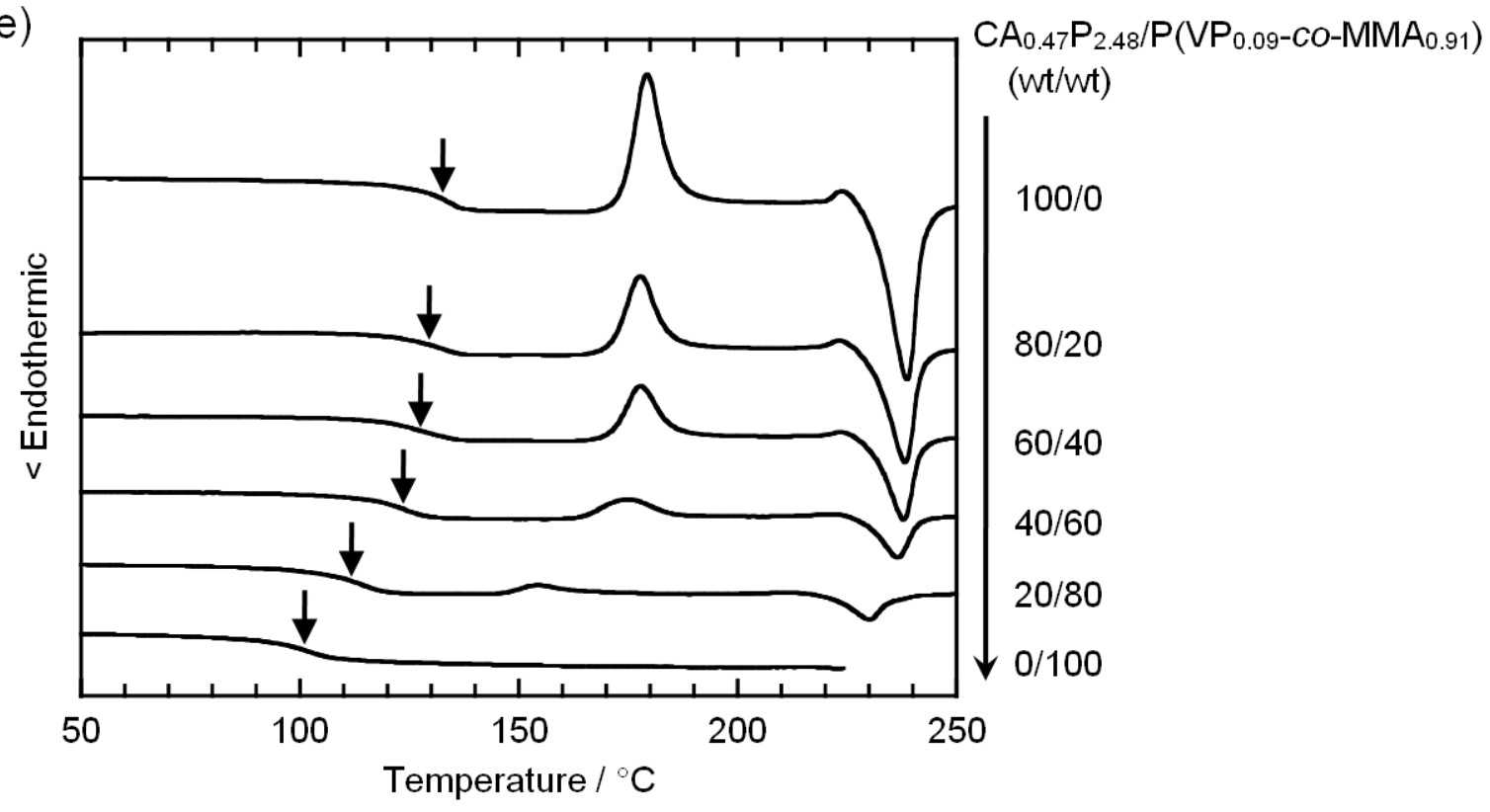


(a)

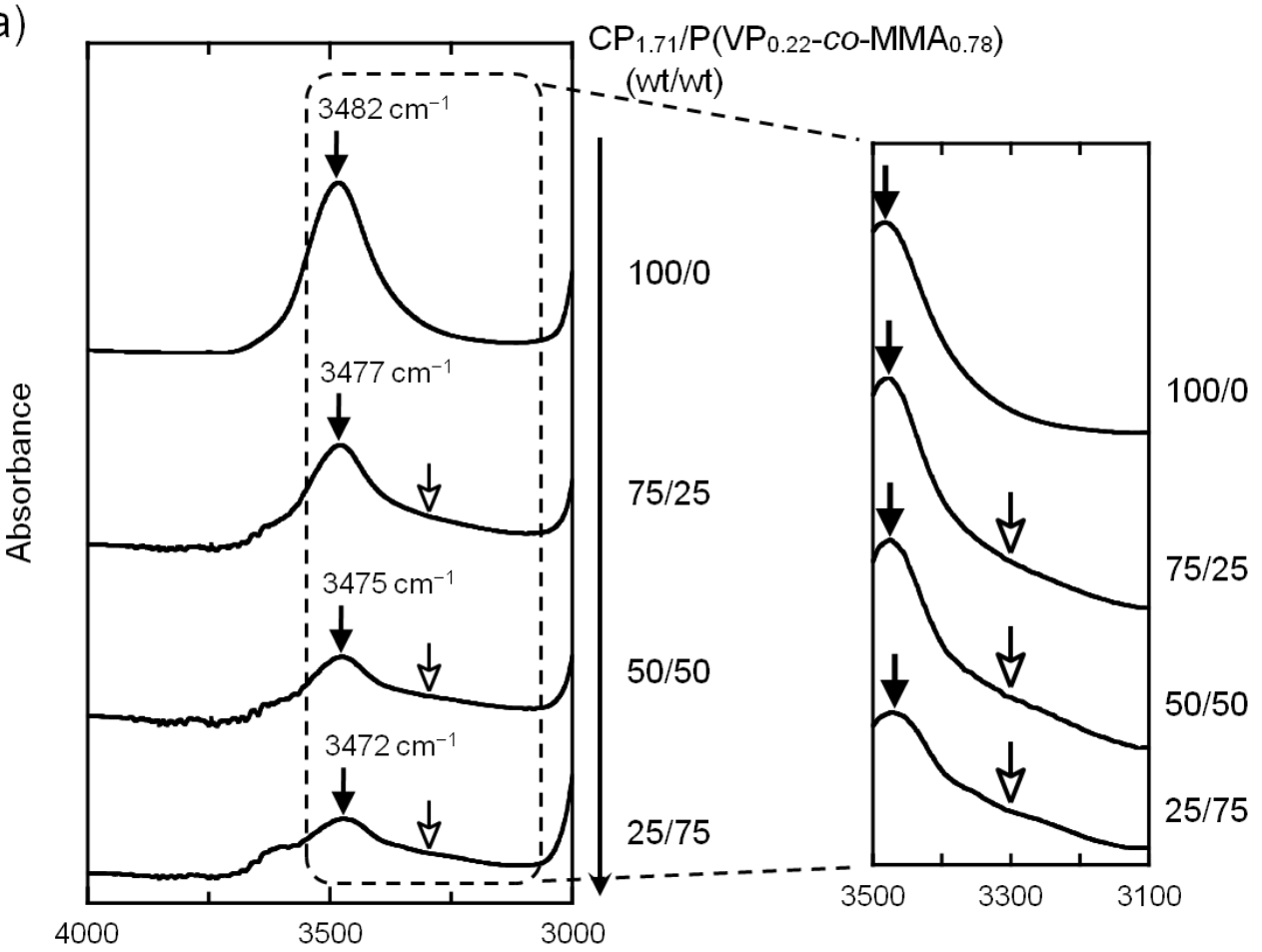

Wavenumber $/ \mathrm{cm}^{-1}$

(b)

b)

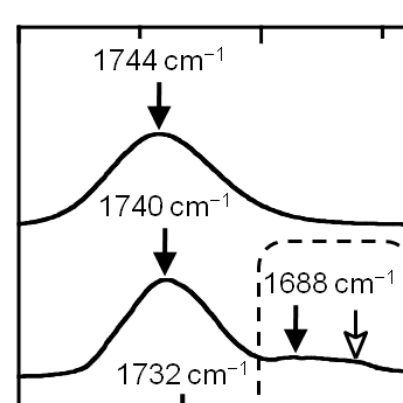

1800
$\mathrm{CP}_{1.71} / \mathrm{P}\left(\mathrm{VP}_{0.22}-\mathrm{CO}-\mathrm{MMA}_{0.78}\right)$

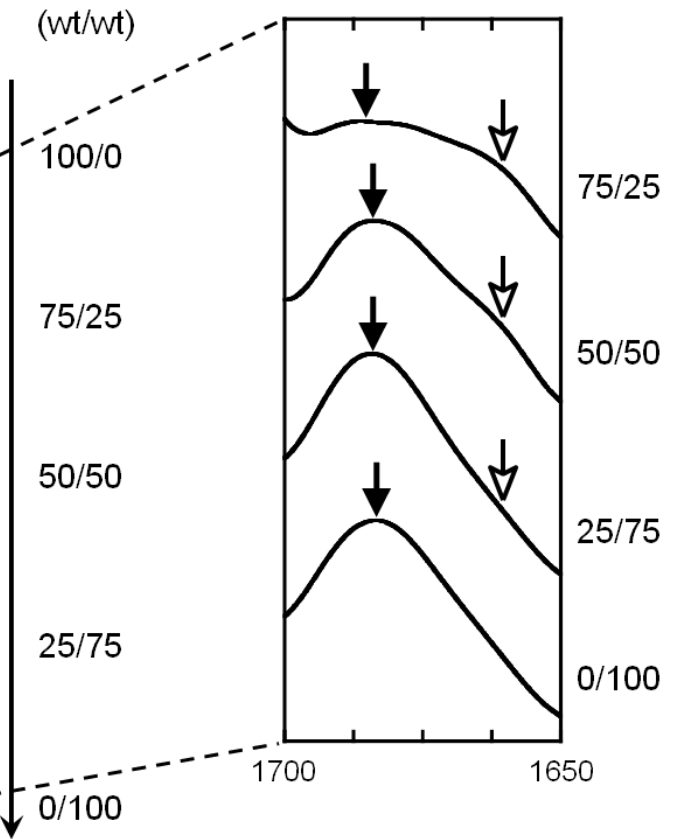



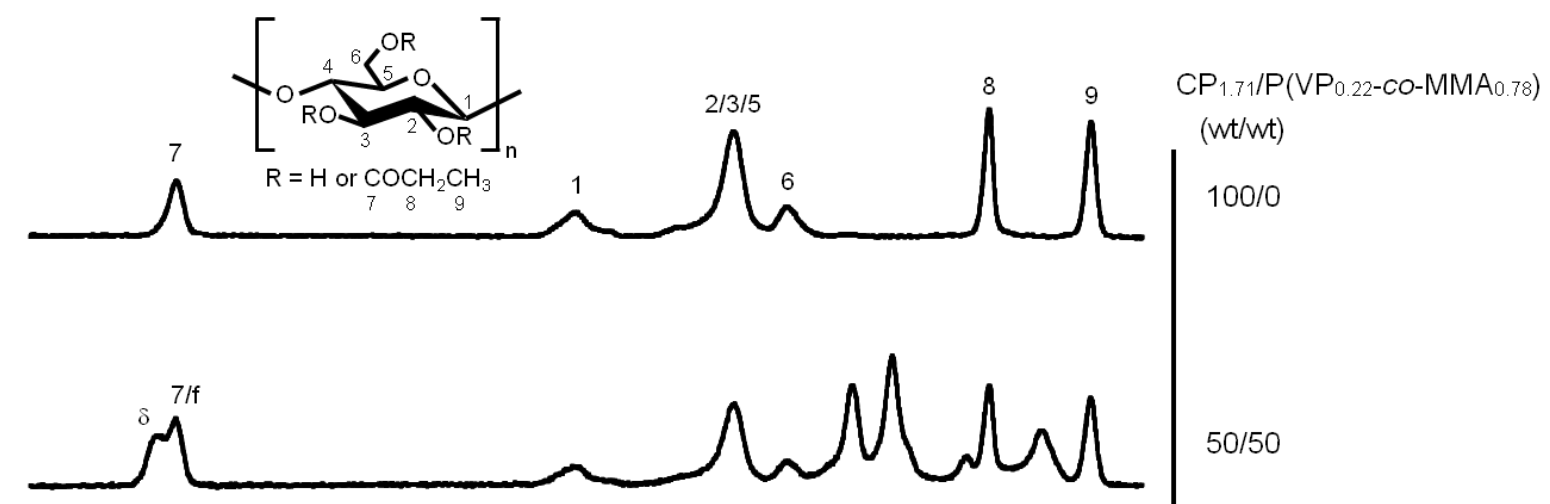

$50 / 50$

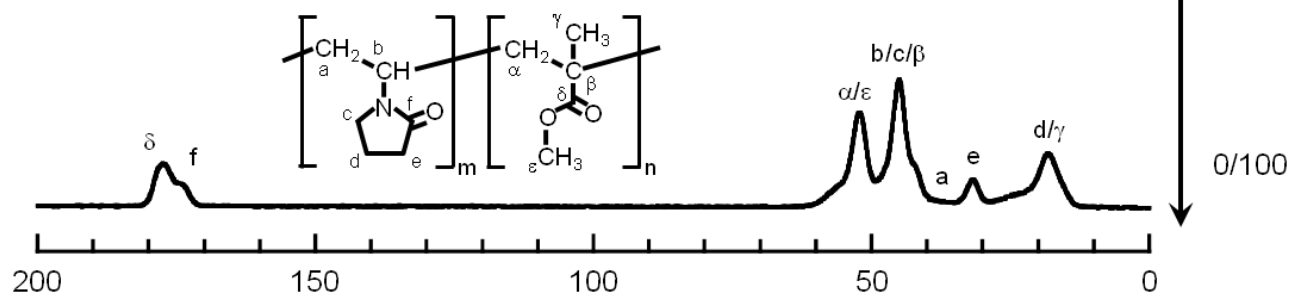

Chemical shift / ppm

$<<$ Fig. 5. $>>$ 
(a)

(b)
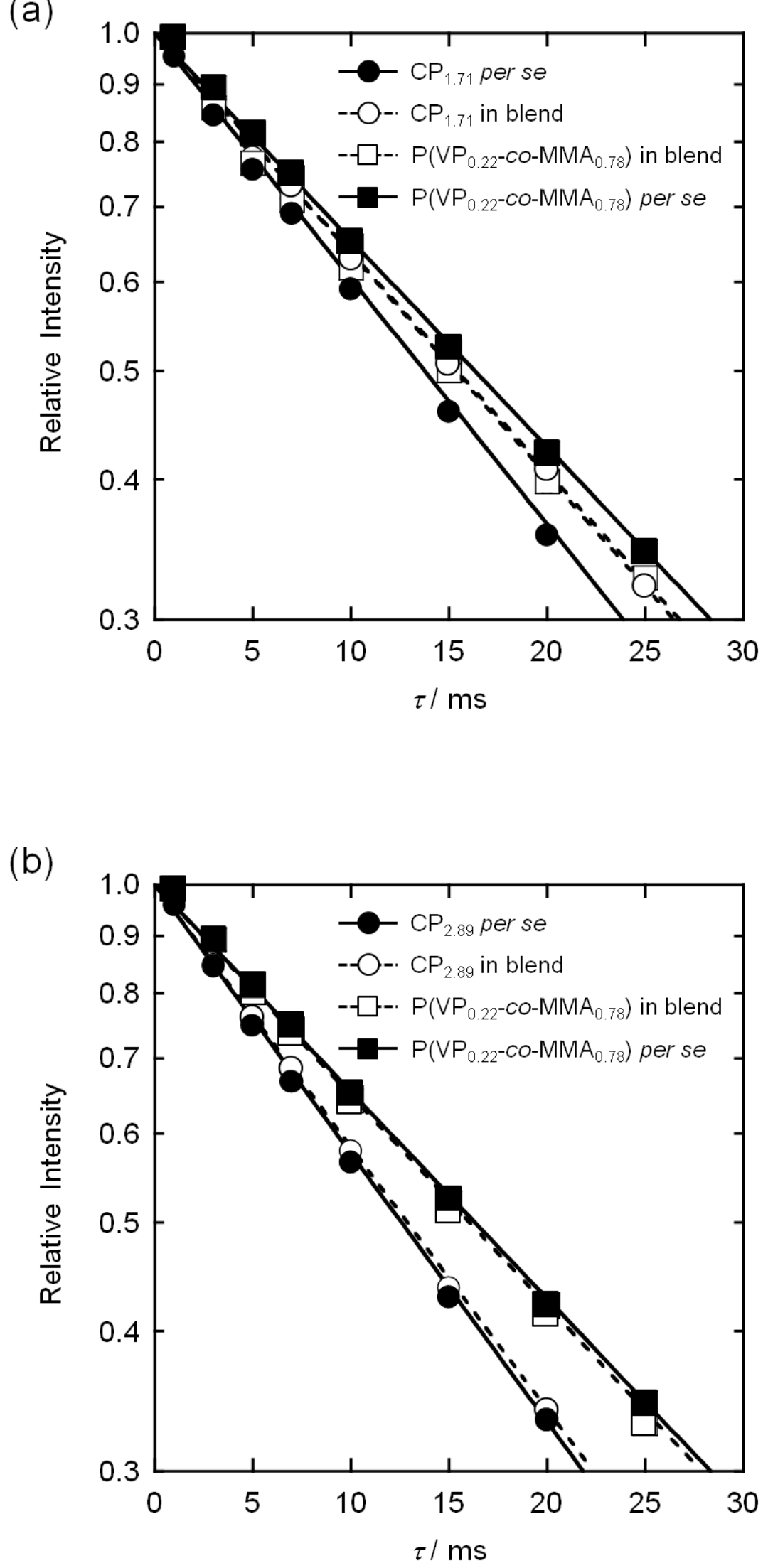


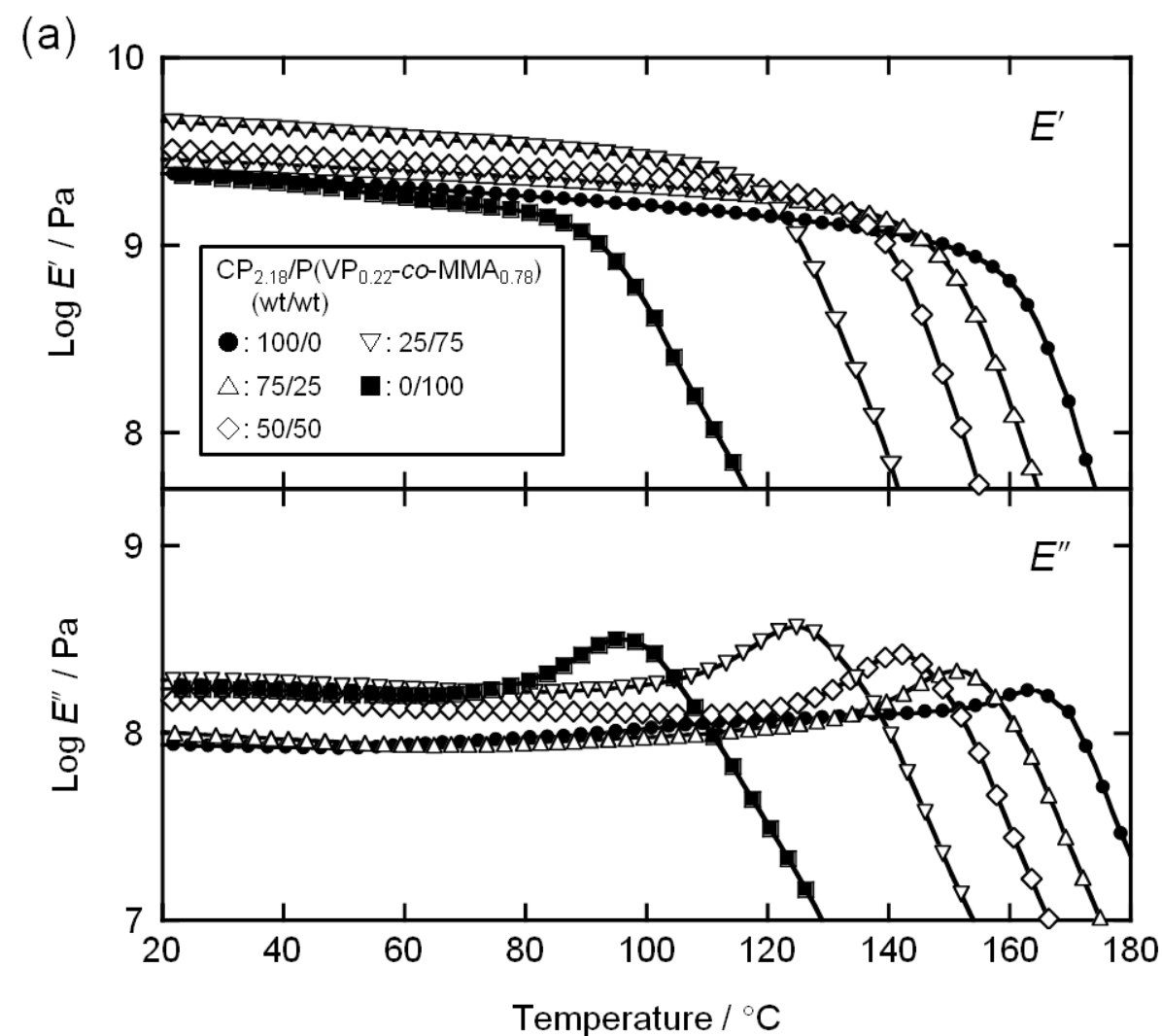

(b)

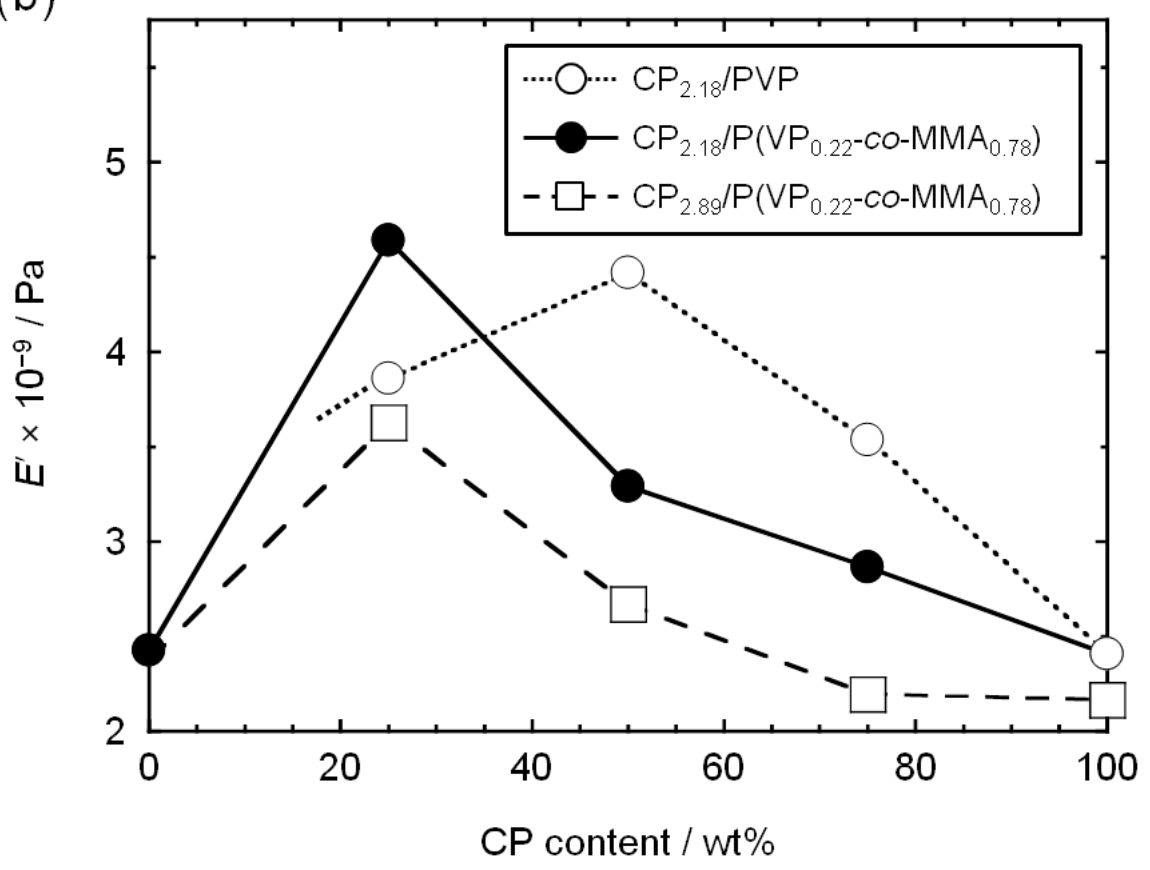




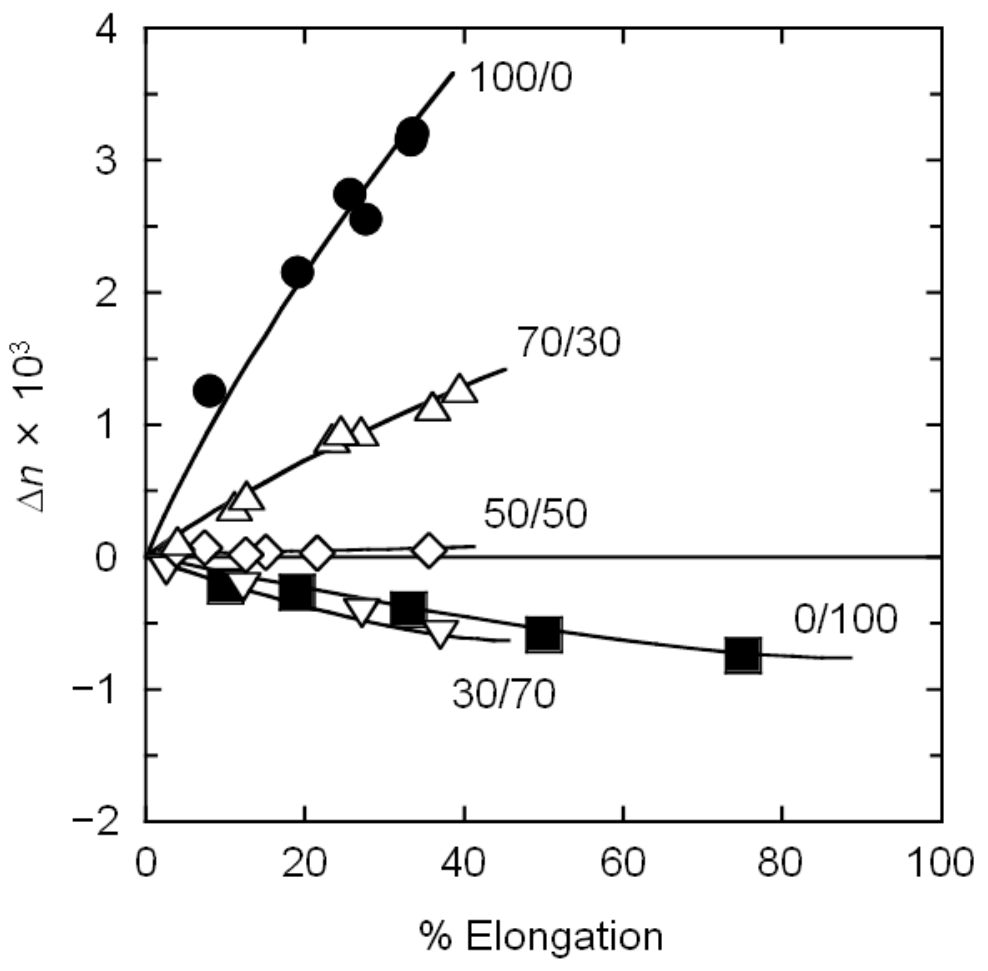

98

<<Fig. 8. >> 
1 Table 1 Characterization of CP, CAP, and vinyl polymers used in the present study

\begin{tabular}{|c|c|c|c|c|c|}
\hline Sample code ${ }^{a}$ & $M_{\mathrm{w}}{ }^{c}$ & $M_{\mathrm{n}}{ }^{c}$ & $M_{\mathrm{w}} / M_{\mathrm{n}}{ }^{c}$ & $T_{\mathrm{g}} /{ }^{\circ} \mathrm{C}$ & Source \\
\hline $\mathrm{CP}_{1.59}$ & $1,230,000$ & 585,000 & 2.10 & 165 & Synthesized \\
\hline $\mathrm{CP}_{1.71}$ & $2,010,000$ & 850,000 & 2.36 & 162 & Synthesized \\
\hline $\mathrm{CP}_{2.09}$ & $1,190,000$ & 571,000 & 2.08 & 160 & Synthesized \\
\hline $\mathrm{CP}_{2.18}$ & $1,300,000$ & 577,000 & 2.25 & 157 & Synthesized \\
\hline $\mathrm{CP}_{2.33}$ & 844,000 & 258,000 & 3.27 & 155 & Synthesized \\
\hline $\mathrm{CP}_{2.53}$ & 818,000 & 367,000 & 2.23 & 141 & Synthesized \\
\hline $\mathrm{CP}_{2.62}$ & 979,000 & 359,000 & 2.73 & 138 & Synthesized \\
\hline $\mathrm{CP}_{2.72}$ & $2,390,000$ & 968,000 & 2.47 & 134 & Synthesized \\
\hline $\mathrm{CP}_{2.81}$ & $1,990,000$ & 837,000 & 2.38 & 128 & Synthesized \\
\hline $\mathrm{CP}_{2.89}$ & $2,000,000$ & 692,000 & 2.89 & 127 & Synthesized \\
\hline $\mathrm{CP}_{2.93}$ & $1,250,000$ & 525,000 & 2.38 & 124 & Synthesized \\
\hline $\mathrm{CA}_{0.16} \mathrm{P}_{2.52}$ & 258,000 & 73,400 & 3.51 & 143 & Eastman Chemical Co. \\
\hline $\mathrm{CA}_{0.47} \mathrm{P}_{2.48}$ & 240,000 & 98,500 & 2.44 & 132 & Synthesized \\
\hline Sample code ${ }^{b}$ & $M_{\mathrm{w}}^{d}$ & $M_{\mathrm{n}}{ }^{d}$ & $M_{\mathrm{w}} / M_{\mathrm{n}}{ }^{d}$ & $T_{\mathrm{g}} /{ }^{\circ} \mathrm{C}$ & Source \\
\hline PVP & $360,000^{e}$ & - & - & 177 & Nacalai Tesque, Inc. \\
\hline $\mathrm{P}\left(\mathrm{VP}_{0.76^{-}}\right.$co- $\left.\mathrm{MMA}_{0.24}\right)$ & 78,700 & 31,400 & 2.51 & 121 & Synthesized $^{f}$ \\
\hline $\mathrm{P}\left(\mathrm{VP}_{0.67}-c o-\mathrm{MMA}_{0.33}\right)$ & 204,000 & 55,100 & 3.70 & 134 & Synthesized $^{f}$ \\
\hline $\mathrm{P}\left(\mathrm{VP}_{0.61}-c o-\mathrm{MMA}_{0.39}\right)$ & 193,000 & 52,700 & 3.66 & 121 & Synthesized $^{f}$ \\
\hline $\mathrm{P}\left(\mathrm{VP}_{0.50}-c o-\mathrm{MMA}_{0.50}\right)$ & 184,000 & 61,300 & 3.00 & 119 & Synthesized ${ }^{f}$ \\
\hline $\mathrm{P}\left(\mathrm{VP}_{0.46}-c o-\mathrm{MMA}_{0.54}\right)$ & 257,000 & 91,100 & 2.82 & 112 & Synthesized ${ }^{f}$ \\
\hline $\mathrm{P}\left(\mathrm{VP}_{0.42}-c o-\mathrm{MMA}_{0.58}\right)$ & 288,000 & 108,000 & 2.67 & 117 & Synthesized ${ }^{f}$ \\
\hline $\mathrm{P}\left(\mathrm{VP}_{0.32}-c o-\mathrm{MMA}_{0.68}\right)$ & 97,300 & 37,800 & 2.57 & 104 & Synthesized ${ }^{f}$ \\
\hline $\mathrm{P}\left(\mathrm{VP}_{0.22}-c o-\mathrm{MMA}_{0.78}\right)$ & 189,000 & 70,800 & 2.66 & 111 & Synthesized ${ }^{f}$ \\
\hline $\mathrm{P}\left(\mathrm{VP}_{0.13}-c o-\mathrm{MMA}_{0.87}\right)$ & 91,800 & 44,100 & 2.08 & 100 & Synthesized $^{f}$ \\
\hline $\mathrm{P}\left(\mathrm{VP}_{0.09}-c o-\mathrm{MMA}_{0.91}\right)$ & 97,800 & 47,300 & 2.07 & 101 & Synthesized $^{f}$ \\
\hline PMMA & 88,400 & 35,000 & 2.53 & 100 & Aldrich Chemical Co. \\
\hline
\end{tabular}

${ }^{a}$ The DS values were determined by ${ }^{1} \mathrm{H}$ NMR.

${ }^{b}$ The VP contents were determined by FT-IR in a way described by Liu et al. (1994).

${ }^{c}$ Determined by gel permeation chromatography (mobile phase, tetrahydrofuran at $40{ }^{\circ} \mathrm{C}$ ) with polystyrene standards.

${ }^{d}$ Determined by gel permeation chromatography (mobile phase, $10 \mathrm{mM} \mathrm{L}^{-1}$ lithium bromide/DMF at $40{ }^{\circ} \mathrm{C}$ ) with polystyrene standards.

${ }^{e}$ Nominal value.

${ }^{f}$ Synthesized in our laboratory by radical polymerization of two distilled monomers, VP (Nacalai Tesque, Inc.) and MMA (Nacalai Tesque, Inc.), in the same way as that described in a previous paper (Ohno \& Nishio, 2007a). 
2 Table $2 T_{1 \rho}{ }^{\mathrm{H}}$ values obtained for two series of blends, $\mathrm{CP}_{1.71} / \mathrm{P}\left(\mathrm{VP}_{0.22}\right.$-co-MMA $\left.\mathrm{M}_{0.78}\right)$ and

$3 \quad \mathrm{CP}_{2.89} / \mathrm{P}\left(\mathrm{VP}_{0.22}-\mathrm{co}-\mathrm{MMA}_{0.78}\right)$

\begin{tabular}{|c|c|c|c|c|c|c|c|c|}
\hline \multirow{3}{*}{$\begin{array}{c}\mathrm{CP}_{1.71} / \mathrm{P}\left(\mathrm{VP}_{0.22}-c o-\mathrm{MMA}_{0.78}\right) \\
(\mathrm{wt} / \mathrm{wt})\end{array}$} & \multicolumn{8}{|c|}{$T_{1 \rho}^{\mathrm{H}} / \mathrm{ms}$} \\
\hline & \multicolumn{4}{|c|}{$\mathrm{CP}_{1.71}$} & \multicolumn{4}{|c|}{$\mathrm{P}\left(\mathrm{VP}_{0.22}-c o-\mathrm{MMA}_{0.78}\right)$} \\
\hline & $\mathrm{C} 2 / 3 / 5$ & $\mathrm{C} 8$ & C9 & Ave. & $\alpha / \varepsilon$ & $\mathrm{b} / \mathrm{c} / \beta$ & $\mathrm{d} / \gamma$ & Ave. \\
\hline $100 / 0$ & 20.5 & 20.3 & 19.2 & 20.0 & - & - & - & - \\
\hline $75 / 25$ & 21.2 & 21.6 & 20.5 & 21.1 & 21.2 & 21.5 & 21.2 & 21.3 \\
\hline $50 / 50$ & 22.2 & 22.8 & 21.7 & 22.2 & 22.1 & 22.1 & 22.4 & 22.2 \\
\hline $25 / 75$ & 23.1 & 22.9 & 22.9 & 23.0 & 22.9 & 23.0 & 22.8 & 22.9 \\
\hline $0 / 100$ & - & - & - & - & 23.3 & 23.5 & 24.0 & 23.6 \\
\hline \multirow{3}{*}{$\begin{array}{c}\mathrm{CP}_{2.89} / \mathrm{P}\left(\mathrm{VP}_{0.22}-c o-\mathrm{MMA}_{0.78}\right) \\
(\mathrm{wt} / \mathrm{wt})\end{array}$} & \multicolumn{8}{|c|}{$T_{1 \rho}^{\mathrm{H}} / \mathrm{ms}$} \\
\hline & \multicolumn{4}{|c|}{$\mathrm{CP}_{2.89}$} & \multicolumn{4}{|c|}{$\mathrm{P}\left(\mathrm{VP}_{0.22}-c o-\mathrm{MMA}_{0.78}\right)$} \\
\hline & $\mathrm{C} 2 / 3 / 5$ & $\mathrm{C} 8$ & C9 & Ave. & $\alpha / \varepsilon$ & $\mathrm{b} / \mathrm{c} / \beta$ & $\mathrm{d} / \gamma$ & Ave. \\
\hline $100 / 0$ & 18.5 & 17.6 & 17.7 & 17.9 & - & - & - & - \\
\hline $75 / 25$ & 18.9 & 19.5 & 18.7 & 19.0 & 22.7 & 23.5 & 23.2 & 23.1 \\
\hline $50 / 50$ & 18.8 & 18.5 & 19.2 & 18.8 & 23.3 & 23.4 & 23.1 & 23.3 \\
\hline $25 / 75$ & 18.9 & 18.6 & 18.8 & 18.8 & 23.1 & 22.6 & 23.7 & 23.1 \\
\hline $0 / 100$ & - & - & - & - & 23.3 & 23.5 & 24.0 & 23.6 \\
\hline
\end{tabular}

